\title{
A pyridinium derivative from Red Sea soft corals inhibited voltage-activated potassium conductances and increased excitability of rat cultured sensory neurones
}

\author{
Tarek A Temraz¹, Wael E Houssen², Marcel Jaspars², David R Woolley², \\ Kerrie N Wease ${ }^{3}$, Steven N Davies ${ }^{3}$ and Roderick H Scott*3
}

Address: ${ }^{1}$ Marine Science Department, Suez Canal University, Ismailia, Egypt, ${ }^{2}$ Marine Natural Products Laboratory, Department of Chemistry, University of Aberdeen, Old Aberdeen, AB24 3UE, Scotland, UK and ${ }^{3}$ College of Medical Sciences, Institute of Medical Science, The University of Aberdeen, Foresterhill, Aberdeen AB25 2ZD, Scotland, U.K

Email: Tarek A Temraz - ttemraz@yahoo.com; Wael E Houssen - w.houssen@abdn.ac.uk; Marcel Jaspars - m.jaspars@abdn.ac.uk; David R Woolley - d.r.woolley@abdn.ac.uk; Kerrie N Wease - kerriewease@hotmail.com; Steven N Davies - s.n.davies@abdn.ac.uk; Roderick H Scott* - rod.scott@abdn.ac.uk

* Corresponding author

Published: 06 July 2006

BMC Pharmacology 2006, 6:10 doi:10.1186/1471-2210-6-10

This article is available from: http://www.biomedcentral.com/I47/-22/0/6/10

(c) 2006 Temraz et al; licensee BioMed Central Ltd.

This is an Open Access article distributed under the terms of the Creative Commons Attribution License (http://creativecommons.org/licenses/by/2.0), which permits unrestricted use, distribution, and reproduction in any medium, provided the original work is properly cited.

\begin{abstract}
Background: Whole cell patch clamp recording and intracellular $\mathrm{Ca}^{2+}$ imaging were carried out on rat cultured dorsal root ganglion (DRG) neurones to characterize the actions of crude extracts and purified samples from Red Sea soft corals. The aim of the project was to identify compounds that would alter the excitability of DRG neurones.

Results: Crude extracts of Sarcophyton glaucum and Lobophyton crassum attenuated spike frequency adaptation causing DRG neurones to switch from firing single action potentials to multiple firing. The increase in excitability was associated with enhanced $\mathrm{KCl}$-evoked $\mathrm{Ca}^{2+}$ influx. The mechanism of action of the natural products in the samples from the soft corals involved inhibition of voltageactivated $\mathrm{K}^{+}$currents. An active component of the crude marine samples was identified as 3carboxy-I-methyl pyridinium (trigonelline). Application of synthetic 3-carboxy-I-methyl pyridinium at high concentration $(0.1 \mathrm{mM})$ also induced multiple firing and reduced voltage-activated $\mathrm{K}^{+}$ current. The changes in excitability of DRG neurones induced by 3-carboxy-I-methyl pyridinium suggest that this compound contributes to the bioactivity produced by the crude extracts from two soft corals.

Conclusion: Sarcophyton glaucum and Lobophyton crassum contain natural products including 3carboxy-I-methyl pyridinium that increase the excitability of DRG neurones. We speculate that in addition to developmental control and osmoregulation these compounds may contribute to chemical defenses.
\end{abstract}

\section{Background}

The potential benefits of marine pharmacology remain to be fully realised. Diverse and novel natural products iso- lated from bacteria, algae and benthic invertebrates including soft corals, sponges and anemones from distinct marine environments have been chemically identified 
and some of their biological activities characterised [1]. Marine organisms may contain many potential novel drugs because of the unique environmental conditions (high ionic strengths, low light level, cold or warm temperatures, and pressure) found in their habitats. These conditions have led to the biosynthesis of unique compounds [2]. However, such studies are associated with clear difficulties that include the taxonomy of organisms, identification of the origins of bioactive materials, reproducibility of material collection and complex chemistry [3].

The Red Sea has two major distinctive features. It has one highest levels of marine bio-diversity and it has great seasonal fluctuations of air and water temperatures. Conducting research on Red Sea organisms offers unique advantages, in view of the diversity and high endemism of its biota. For example, of the 180 known species of the soft corals, about $40 \%$ are unique to the Red Sea [4].

Several groups of marine organisms including soft-bodied sessile invertebrates, such as tunicates, soft corals, and certain sponges appear defenceless yet they have few predators and are not substrates for fouling micro-organisms. These organisms are rich in nutritionally important substances and use an arsenal of chemical defences and chemical repellents to protect themselves and when competing for space. The incidence of predation is low because of the production of toxic compounds and the possession of some form of calcareous sclerites [5].

In this study we have used the electrophysiological properties of cultured sensory neurones from rat dorsal root ganglia (DRG) as an assay system to identify and characterize the biological activities on ion channel currents of crude extracts and an active purified common compound present in two soft coral samples. The activities of some soft coral toxins are consistent with pore-formation as a mechanism of action and the natural products responsible may be similar to polymeric alkylpyridinium salts from marine sponges [6-9].

Previously, a number of interesting biologically active compounds from soft corals have been studied and these genera are sources of hundreds of different compounds [2]. A few examples include: 1. Sarcophytolide (lactone cembrane diterpene) from Sarcophyton glaucum, which, is antimicrobial and suppresses glutamate-evoked $\mathrm{Ca}^{2+}$ responses and neurone death [10]. 2. Brominated oxylipins from Dendronephthya spp and Tubipora musica, which are toxic to shrimps, sea urchin eggs and crown gall tumors [11]. 3. Singardin a heptacyclic norcembranoid dimer, which shows cytotoxicity against murine leukemia, human melanoma cells, human lung and colon carcinomas [12]. 4. Lophotoxins from a variety of soft corals that are nicotinic acetylchoine receptors antagonists $[13,14]$. 5. Palytoxin, from the genus Palythoa, which is highly poisonous and increases membrane permeability to cations and potently inhibits $\mathrm{Na}^{+} / \mathrm{K}^{+}$ATPase [15]. 6. A C-29 steroid from Lobophytum crassum the biological activity of which is yet to be reported [16]. Ethyl acetate extraction of a single species of soft coral (Lobophytum catalai TixierDurivault) has yielded a number of distinct novel compounds (two cembranoids, nephthenol, furanosesquiterpene, four polyhydroxysterols and mixtures of sesquiterpenes and monohydroxysterols) [17]. The many diverse compounds are produced, some within nematocyst venoms that have hemolytic, dermonecrotic and vasopermeabilising factors [18], others are confined to protective mucus [19], eggs and larvae (pukalide and 11 $\beta$-acetoxypukalide), or are released into the water column during mass spawning [20].

Although we have failed to find a pore forming compound, our research has identified a natural product that can dramatically increase the excitability of cultured sensory neurones and therefore may act as a pronociceptive agent against predators.

\section{Results and discussion Chemical characterization of the soft coral samples and identification of the active compound}

Figure 1 shows pictures of the three species of Red Sea soft corals (Sarcophyton glaucum, Lobophyton crassum \& Sinularia leptoclados), which were the sources of the natural product materials used in this study.

The similarity of the ${ }^{1} \mathrm{H}$ NMR spectra of crude extracts, especially in the region 7-10 ppm, from Sarcophyton glaucum and Lobophyton crassum provided the starting point for comparison of bioactivity. The specimens of Sarcophyton glaucum and Lobophyton crassum were not heavily armoured but were free from fouling organisms indicating that they had efficient chemical defenses. In contrast, Sinularia leptoclados is heavily armoured but does not contain material with a similar ${ }^{1} \mathrm{H}$ NMR spectrum as seen for the other two species. Table 1 shows the NMR data for 3carboxy-1-methyl pyridinium (Fig. 2) obtained in $\mathrm{CD}_{3} \mathrm{OD}$. The low-resolution electron impact mass spectrometry (LREIMS) of 3-carboxy-1-methyl pyridinium showed a pseudomolecular ion $[\mathrm{M}+\mathrm{H}]^{+}$at $m / z$ 138. The high-resolution electron impact mass spectrometry (HREIMS) provided the exact value of $m / z 138.0549(\Delta$ $0.1 \mathrm{mmu}$ ) for $[\mathrm{M}+\mathrm{H}]^{+}$, which corresponded well with the formula $\mathrm{C}_{7} \mathrm{H}_{7} \mathrm{NO}_{2}$. The formula suggested five degrees of unsaturation. The ${ }^{1} \mathrm{H}$ NMR spectrum of 3-carboxy-1methyl pyridinium exhibited signals at $\delta_{\mathrm{H}} 9.33(1 \mathrm{H}, \mathrm{s})$, $8.96(1 \mathrm{H}, \mathrm{s}), 8.95(1 \mathrm{H}, \mathrm{s})$, and $8.11(1 \mathrm{H}, \mathrm{bt})$, whose chemical shifts were reminiscent of those of some pyridine mesomeric betaine alkaloids e.g. pyridinebetaine A [21], 

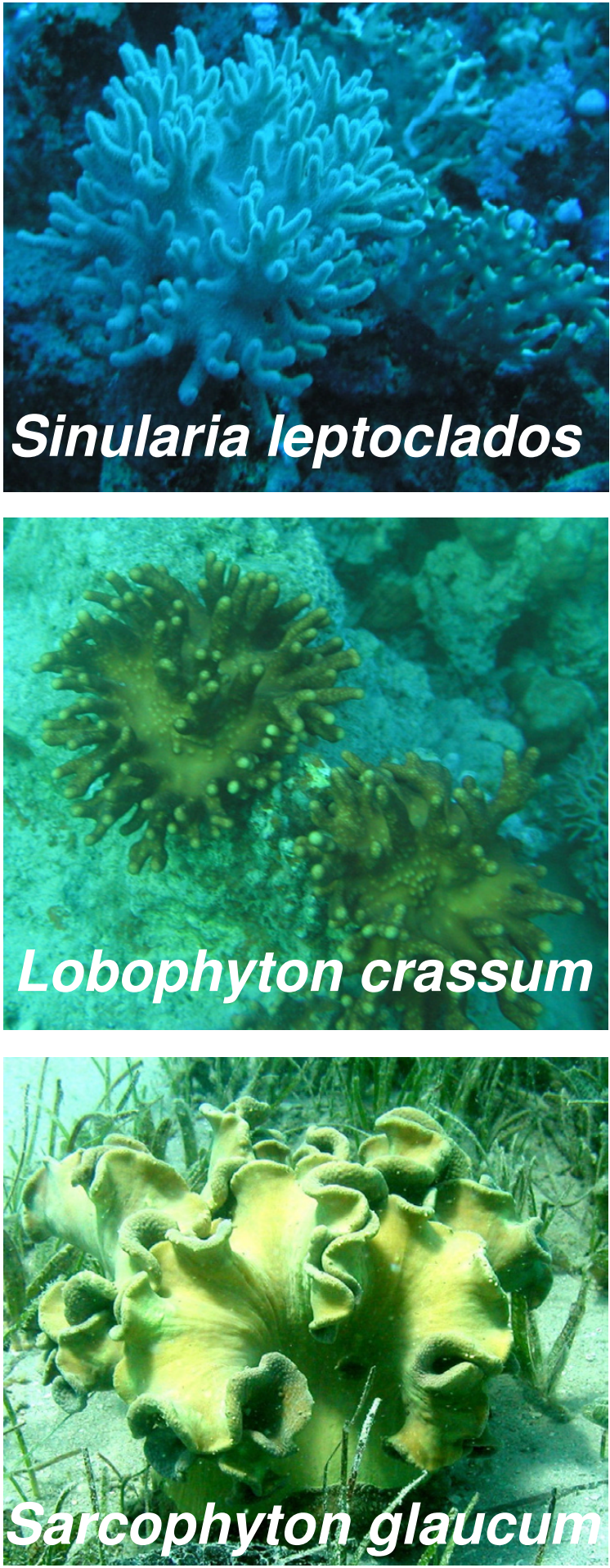

Figure I

Underwater photographs of the species soft corals used in this study. and homarine [22]. These values were assigned to $\mathrm{H}-2, \mathrm{H}-$ 6, H-4 and H-5 protons respectively and their connectivities to their respective carbons $\left(\delta_{\mathrm{C}} 147.0, \mathrm{CH} ; 145.2, \mathrm{CH}\right.$; 147.0, $\mathrm{CH}$ and $127.7, \mathrm{CH}$ ) were determined from a heteronuclear single quantum correlated spectroscopy (HSQC) experiment. The ${ }^{1} \mathrm{H}$ NMR spectrum also exhibited a proton singlet at $\delta_{\mathrm{H}} 4.43(3 \mathrm{H})$, which showed heteronuclear multiple bond correlated spectroscopy (HMBC) correlations with C-2 $\left(\delta_{\mathrm{C}} 147.0, \mathrm{CH}\right)$ and $\mathrm{C}-6\left(\delta_{\mathrm{C}} 145.2, \mathrm{CH}\right)$. This evidence indicated the presence of a methyl group on $\mathrm{N}-1$.

Further database searches led to the identification of the structure as the long-known alkaloid, 3-carboxy-1-methyl pyridinium (trigonelline). Confirmation of the structure was carried out by comparison of our NMR data with spectra from an authentic sample of 3-carboxy-1-methyl pyridinium (trigonelline hydrochloride) as well as with data from a previous study [23].

\section{Actions of crude samples from soft corals on cultured DRG neurone action potential properties}

All the experiments conducted in this study were carried out in the continual presence of extracellular recording solution that contained $0.1 \%$ DMSO. This concentration of DMSO was required to keep the crude extracts from Red Sea soft corals in solution. Under these recording conditions the mean resting membrane potential and input resistance (derived from electrotonic potentials produced by $-100 \mathrm{pA}$ step commands) were $-61 \pm 2 \mathrm{mV}(\mathrm{n}=35)$ and $338 \pm 45 \mathrm{M} \Omega(\mathrm{n}=16)$ respectively. These values are similar to the mean values $(-60 \mathrm{mV}$ and $356 \mathrm{M} \Omega ; \mathrm{n}=12)$, we have previously reported from studies carried out on cultured DRG neurones in the absence of DMSO [6]. DRG neurones are a heterogeneous population of neurones, which show a variety of distinct structural, biochemical and electrophysiological characteristics. To standardize the electrophysiological recordings made from DRG neurones the cells were held at a potential of $-70 \mathrm{mV}$ and depolarized with 100-800 ms current step commands to activate action potentials. Most of our cultured DRG neurones ( $90 \% ; \mathrm{n}=31$ of 34 ) show spike frequency adaptation (accommodation) and fire only a single action potential in response to a prolonged supra-maximal depolarizing current command. In the absence of DMSO we have reported multiple action potential firing in less than $20 \%$ of DRG neurones [24].

The recording method, animal species and culture conditions may influence multiple firing levels in sensory neurones and the incidence is higher in some other studies. For example previous work on whole nodose ganglia and ganglia slices showed that $38.5 \%$ of C-fibre neurones and $66.7 \%$ of A-fibre neurones show multiple firing properties [25]. 
Table I: ID and 2D NMR spectral data for 3-carboxy-I-methyl pyridinium obtained in $C_{3} O D$ ( $\delta$ in ppm).

\begin{tabular}{|c|c|c|c|c|c|}
\hline \multirow{2}{*}{$\begin{array}{c}\text { No. } \\
2\end{array}$} & \multicolumn{2}{|c|}{$\delta_{\mathrm{C}}$} & \multirow{2}{*}{$\begin{array}{c}\delta_{\mathrm{H}}(\# \mathrm{H}, \mathrm{m}, \mathrm{J} / \mathrm{Hz}) \\
9.33(\mathrm{IH}, \mathrm{s})\end{array}$} & \multirow{2}{*}{$\begin{array}{c}\text { 'H-IH COSY } \\
\text { H-6, H-8 }\end{array}$} & \multirow{2}{*}{$\begin{array}{c}\text { HMBC }\left(\delta_{C} \text { to } \delta_{H}\right) \\
H-4, H-6, H-8\end{array}$} \\
\hline & 147.0 & $\mathrm{CH}$ & & & \\
\hline 3 & 162.0 & $\mathrm{qC}$ & & & \\
\hline 4 & 147.0 & $\mathrm{CH}$ & $8.95(\mathrm{IH}, \mathrm{s})$ & $\mathrm{H}-5$ & $\mathrm{H}-2, \mathrm{H}-5, \mathrm{H} 6$ \\
\hline 5 & 127.7 & $\mathrm{CH}$ & 8. II (IH, bt) & $\mathrm{H}-4, \mathrm{H}-6$ & $\mathrm{H}-4, \mathrm{H}-6$ \\
\hline 6 & 145.2 & $\mathrm{CH}$ & $8.96(\mathrm{IH}, \mathrm{s})$ & $\mathrm{H}-2, \mathrm{H}-5, \mathrm{H}-8$ & $\mathrm{H}-2, \mathrm{H}-4, \mathrm{H}-8$ \\
\hline 7 & 166.0 & $\mathrm{qC}$ & & & \\
\hline 8 & 47.6 & $\mathrm{CH}_{3}$ & $4.43(3 \mathrm{H}, \mathrm{s})$ & $\mathrm{H}-2, \mathrm{H}-6$ & $\mathrm{H}-6$ \\
\hline
\end{tabular}

Increasing the duration or amplitude of the stimulus does not increase the firing frequency in neurones that show spike frequency adaptation (Fig. 3A \&3B). However, some cultured DRG neurones do not show spike frequency adaptation and fire increasing numbers of action potentials at higher frequencies as the amplitudes of current step commands are increased (Fig. 3B \&3C).

Application of a crude sample from Sarcophyton glaucum (c.Sg; $100 \mu \mathrm{g} / \mathrm{mL}$ ) for $3-5$ minutes induced a dramatic increase in action potential firing. In six neurones that showed spike frequency adaptation, c.Sg increased the number of action potentials evoked during $100 \mathrm{~ms}$ supramaximal current commands from 1 action potential to a mean of $4 \pm 1(\mathrm{n}=6 ; P<0.05)$. The number of action potentials was dependent on the amplitude and duration of the stimulus (Fig. 4A). Similarly, application of a crude sample from Lobophyton crassum (c.Lobo; $100 \mu \mathrm{g} / \mathrm{mL}$ ) for 3-5 minutes also induced increases in action potential firing (Fig. 4B). In five neurones that showed spike frequency adaptation under control conditions, c.Lobo increased the number of action potentials evoked during 100 ms supra-maximal current commands from 1 action potential to a mean of $3 \pm 1(\mathrm{n}=5 ; P<0.03)$. Furthermore, both c.Sg and c.Lobo samples reduced the ampli-

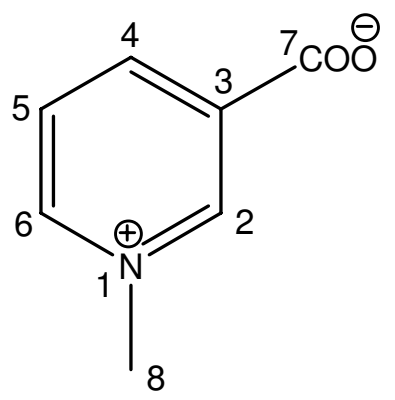

\section{Figure 2}

Structure of 3-carboxy-I-methyl pyridinium (CMP; trigonelline). tudes of the current stimuli required for the thresholds of action potential firing to be reached (Figure 4A \&4B).

These responses developed gradually and in some cases continued to develop over 20 minutes after perfusion of the crude sample was stopped. However, recovery from these effects was seen after 45 minutes and reapplication of either of the crude soft coral extracts could produce repeatable responses. Figure 4C illustrates some example records of action potential firing patterns evoked by +60 $\mathrm{pA}$ and $+120 \mathrm{pA}$ step commands, which show the features of the crude samples actions. These actions included an increased sensitivity to depolarizing current and a reversible lose of spike frequency adaptation. These effects were produced without any significant change in the resting membrane potential.

Increasing the duration of the stimulus to $500 \mathrm{~ms}$ revealed further characteristics of the excitatory actions of the crude soft coral samples. Figure 5A shows the diversity of the maximum levels of excitation achieved following three minutes application of $100 \mu \mathrm{g} / \mathrm{mL}$ c.Lobo that continued to develop during 5 minutes recovery. In these cases $400-$ $600 \mathrm{pA}$ depolarizing currents activated between 7 and 15 action potentials in $500 \mathrm{~ms}$. However, the features of the multiple firing induced by c.Lobo were characterized by a gradual decline in action potential amplitude, a progressive failure in membrane potential repolarization and a gradual upward drift in the depolarizing electrotonic potential (Fig. 5B). In some cases, the drift in the depolarizing electrotonic potential was not dependent on action potentials but could also be seen to produce unusual irregular firing patterns where action potentials were observed only at the beginning and end of the stimulus. The striking effects on action potential firing of c.Sg and c.Lobo, which had similar ${ }^{1} \mathrm{H}$ NMR spectra (region $7-10$ $\mathrm{ppm}$ ), were not seen when $100 \mu \mathrm{g} / \mathrm{mL}$ of crude sample from Sinularia leptoclados (c.Sl) was applied to DRG neurones. The same neurones that were unaffected by the sample from Sinularia leptoclados were sensitive to repeated application of c.Lobo (Fig. 5C). These data suggest that chemical entities common to both c.Sg and c.Lobo and possibly detected by NMR may be responsible for their actions on DRG action potentials. 

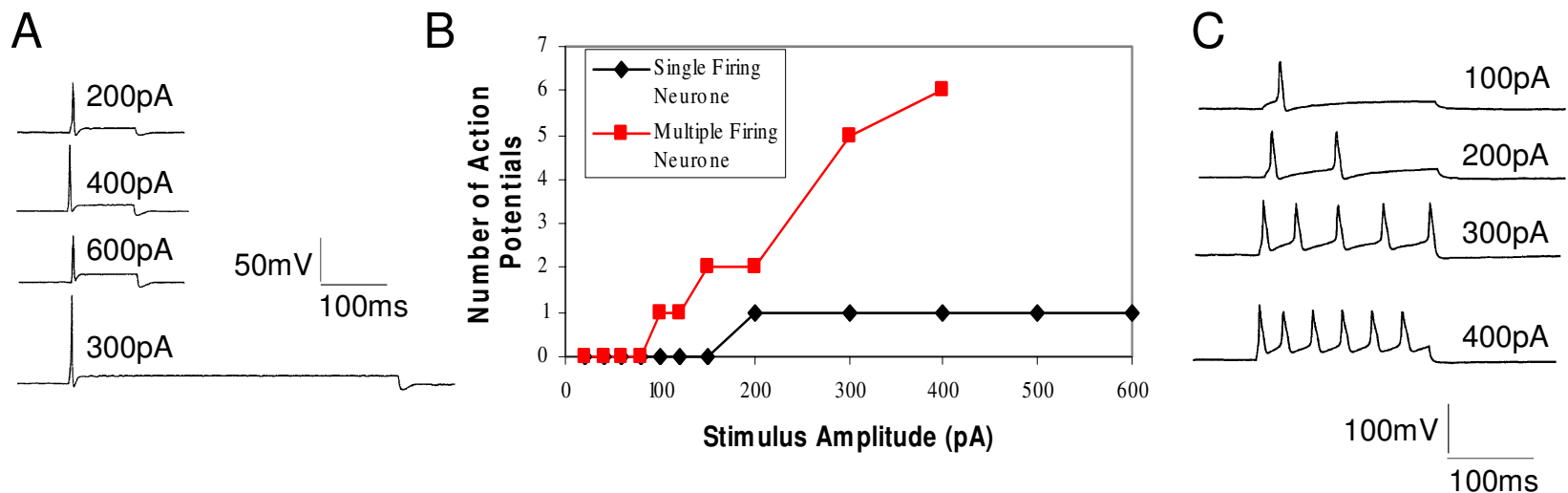

\section{Figure 3}

Comparison of electrophysiological activity between a single firing DRG neurone and a multiple firing DRG neurone. A) Traces showing the single action potential firing of a DRG, stimulated with 200, 400 and 600 pA depolarizing step commands and a prolonged 500 ms stimulus. B) Line graph illustrating the effect of increasing current commands on both single (blue line) and multiple action potential firing (red line) DRG neurones. C) Traces showing the effects of increasing stimulus amplitude (I00$400 \mathrm{pA}$ ) on a multiple action potential firing DRG neurone. An increase in stimulus amplitude leads to an increase in the number of action potentials. In all cases the DRG neurones were held at $-70 \mathrm{mV}$ before stimulation.

The multiple action potential firing patterns induced by c.Sg and c.Lobo were distinct from the control multiple firing observed in a small proportion of DRG neurones. Figure 6 shows example records of the actions of c.Sg (100 $\mu \mathrm{g} / \mathrm{mL}$ ) on a DRG neurone, which under control conditions showed multiple firing. Three minutes application of c.Sg did not attenuate action potential firing but resulted in a gradual decline in action potential amplitude, an increase in action potential duration and a progressive failure in complete action potential repolarization.

The electrotonic responses to depolarizing current commands indicated that c.Sg and c.Lobo may influence rectification in DRG neurones. This was investigated by generating current-voltage relationships in the presence and absence of $100 \mu \mathrm{g} / \mathrm{mL}$ c.Sg (Fig. 7A) or $100 \mu \mathrm{g} / \mathrm{mL}$ c.Lobo. Three to five minutes application of c.Sg $(n=4)$ or c.Lobo $(n=4)$ had no significant effect on the mean electrotonic potential produced by $-60 \mathrm{pA}$ (combined control $-15 \pm 3 \mathrm{mV}$; crude sample $-17 \pm 3 \mathrm{mV}(\mathrm{n}=8$; NS)). In contrast the mean depolarizing electrotonic potential produced by +60 pA step commands increased, an indication of a reduction in the rectification (Fig. 7B). Under control conditions the mean electrotonic potential was $8 \pm 1 \mathrm{mV}$ and in the presence of c.Sg or c.Lobo the combined value increased to $11 \pm 2 \mathrm{mV}(\mathrm{n}=8 ; P<0.005)$.

The changes in action potential firing properties induced by soft coral extracts could have resulted from modulation of voltage-activated $\mathrm{Na}^{+}$channels. To investigate this we studied the properties of single action potentials evoked by $5 \mathrm{~ms}$ depolarizing currents. Action potential firing threshold and amplitude were not significantly altered by the soft coral extracts $(100 \mu \mathrm{g} / \mathrm{ml})$. Under control conditions and in the presence of soft coral extracts the threshold for firing $(-34 \pm 1 \mathrm{mV} \&-35 \pm 1 \mathrm{mV})$ and peak action potential amplitude $(31 \pm 2 \mathrm{mV} \& 34 \pm 2 \mathrm{mV} ; \mathrm{n}=12)$ were unchanged. However, the mean action potential duration at $50 \%$ of peak amplitude was increased from $2 \pm 0.1 \mathrm{~ms}$ to $2.8 \pm 0.1 \mathrm{~ms}(\mathrm{n}=12 ; \mathrm{P}<0.005)$ by the soft coral extracts.

Given the effects of two crude extracts on action potential duration and firing we decided to investigate whether the increases in excitatory properties of DRG neurones were accompanied by increases in intracellular $\mathrm{Ca}^{2+}$ concentration evoked by depolarization.

\section{Actions of crude extracts from soft corals on intracellular calcium in DRG neurones}

The crude soft coral extracts also modulated increases in intracellular $\mathrm{Ca}^{2+}$ evoked by $\mathrm{KCl}(30 \mathrm{mM})$ stimulation. In particular, both c.Sg and c.Lobo increased KCl-evoked $\mathrm{Ca}^{2+}$ transients and in a subpopulation of DRG neurones the extracts reduced the threshold for activating a $\mathrm{Ca}^{2+}$ transient (Fig. 8). Detailed analysis of the $\mathrm{Ca}^{2+}$ transients evoked by $\mathrm{KCl}$ showed that total $\mathrm{Ca}^{2+}$ flux was increased significantly $(\mathrm{n}=10)$ by $100 \mu \mathrm{g} / \mathrm{mL}$ c.Sg (Fig. $8 \mathrm{~A})$. Despite this, the nature of the enhancement in individual neurones varied such that there was no significant increase in the mean peak amplitude (Fig. $8 \mathrm{~B}$ ) or width of the 

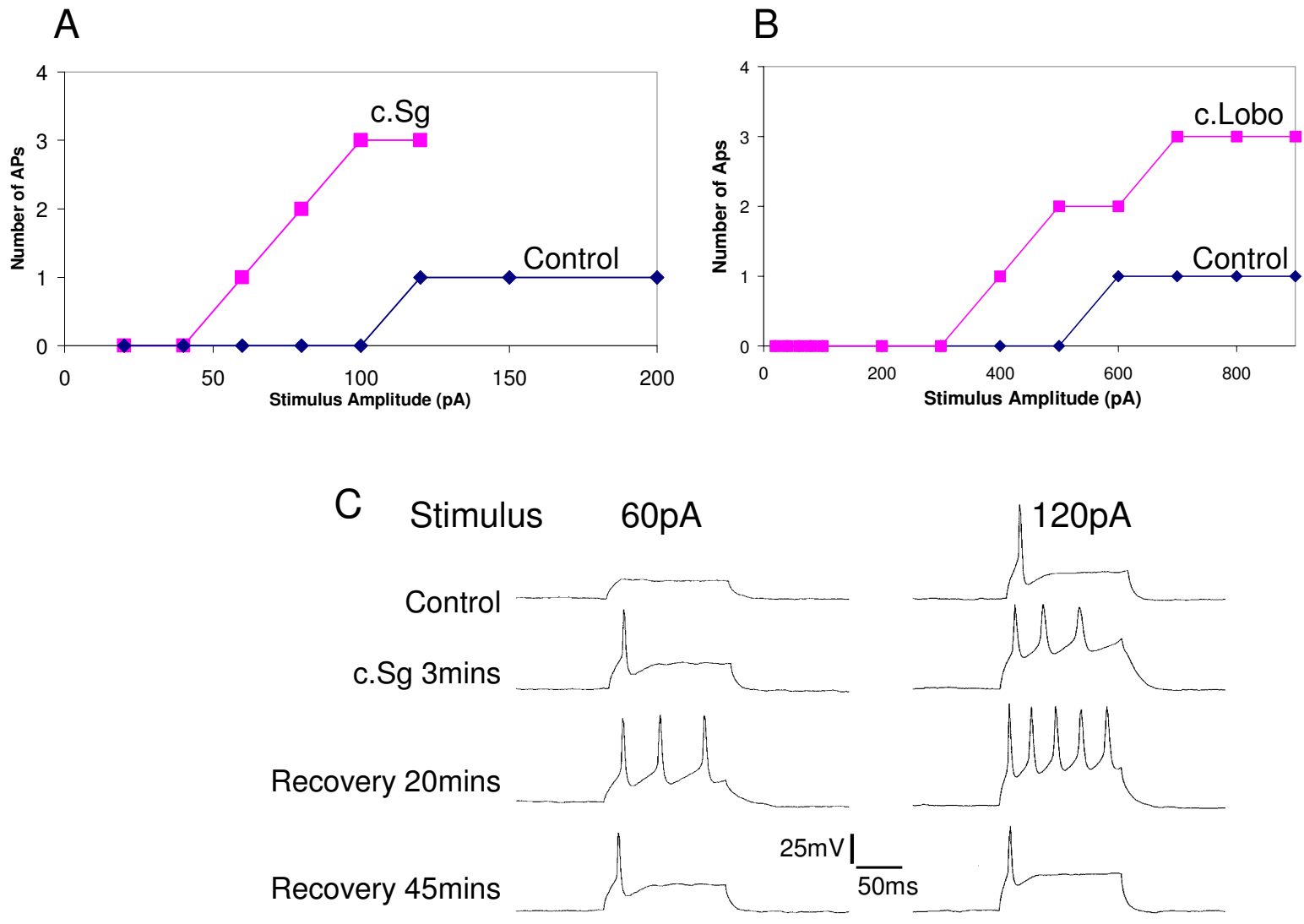

\section{Figure 4}

Application of c.Sg or c.Lobo evoked a switch from single action potential firing to multiple firing in DRG neurones. A) Line graph showing that prior to application of c.Sg $(100 \mu \mathrm{g} / \mathrm{mL})$ only one action potential is evoked over a range of supramaximal stimuli (blue line). Application of c.Sg caused a reduction in threshold stimulus for action potential firing as well as a switch from single to multiple firing (red line). B) Similarly, c.Lobo ( $100 \mu \mathrm{g} / \mathrm{mL})$ reduced the threshold for firing and converted a single firing DRG neurone (blue line) to a multiple firing neurone (red line). C) Current clamp traces illustrate the multiple firing behaviour of neurones that have been exposed to c.Sg. Also seen is the ability of c.Sg to reduce the threshold for firing. Furthermore, recovery is shown 45 minutes after the pressure ejecting c.Sg. In all cases the DRG neurones were held at -70 mV before stimulation.

response at $50 \%$ of peak amplitude $\left(\mathrm{W}_{50} ;\right.$ Fig. $\left.8 \mathrm{C}\right)$. In some cases the peak $\mathrm{Ca}^{2+}$ transient amplitudes were clearly increased by c.Sg (Fig. 8D) but in other neurones the amplitudes were not increased but the durations of the responses were increased and in some instances appeared to show multiple peaks (Fig. 8E). The actions of c.Sg on $\mathrm{Ca}^{2+}$ transients appeared to be reversible (Fig. 8D \&8E). However, some caution is necessary in the interpretation of the results as the decline in the third response to $\mathrm{KCl}$ may result from $\mathrm{Ca}^{2+}$-induced inactivation of voltageactivated $\mathrm{Ca}^{2+}$ channels brought about by the increased intracellular $\mathrm{Ca}^{2+}$ loads. Figure $8 \mathrm{~F}$ shows an example record from a DRG neurone that did not respond to 30
$\mathrm{mM} \mathrm{KCl} \mathrm{stimulation} \mathrm{initially} \mathrm{but} \mathrm{subsequently} \mathrm{responded}$ to $\mathrm{KCl}$ when applied in the presence of c.Sg. This phenomena occurred in 14 out of 24 DRG neurones and interestingly these neurones responded to a third $\mathrm{KCl}$ pulse applied alone after priming with c.Sg. This data is of particular concern as it suggests that stimulation with $30 \mathrm{mM}$ $\mathrm{KCl}$ may not be sufficient to activate $\mathrm{Ca}^{2+}$ transients in all cultured DRG neurones. Previously, we found that $30 \mathrm{mM}$ $\mathrm{KCl}$ depolarizes DRG neurones by 25 to $30 \mathrm{mV}$. Stimulation with $30 \mathrm{mM} \mathrm{KCl}$ allows consistent $\mathrm{Ca}^{2+}$ transients to be activated though it may bias analysis towards DRG neurones with low thresholds for excitation. 


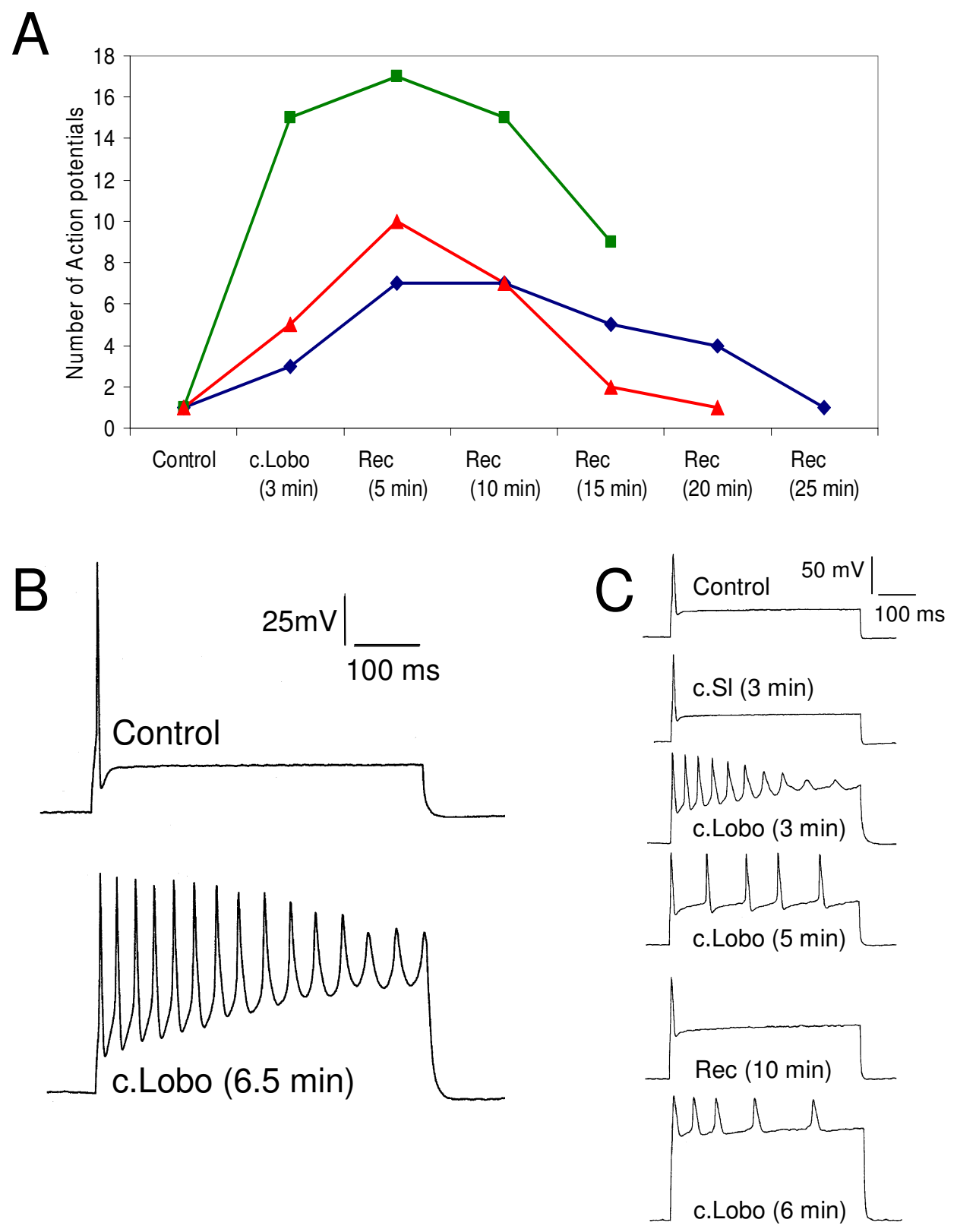

\section{Figure 5}

The effect of c.Lobo and c.SI on cultured DRG neurones. A) Time course showing the action of c.Lobo ( $100 \mu \mathrm{g} / \mathrm{mL})$ in three separate DRG neurones stimulated with 500 ms current step commands. Extracellular application of c.Lobo leads to an increase in the number of action potentials evoked relative to the control. After removal of the drug pipette, an increase in action potential number is followed by a steady decrease to basal levels. B) Voltage traces illustrating the effects that c.Lobo has on both action potential number and action potential shape. C) Voltage traces showing the inability of c.Sl to evoke a switch to multiple firing, followed by application of c.Lobo, which initiates multiple firing. For all records the DRG neurone was stimulated with depolarizing $600 \mathrm{pA}$ step commands. Recovery is seen after removal of c.Lobo and upon further application multiple firing is once again evoked. In all cases the DRG neurones were held at $-70 \mathrm{mV}$ before stimulation. with $500 \mathrm{~ms}$. 


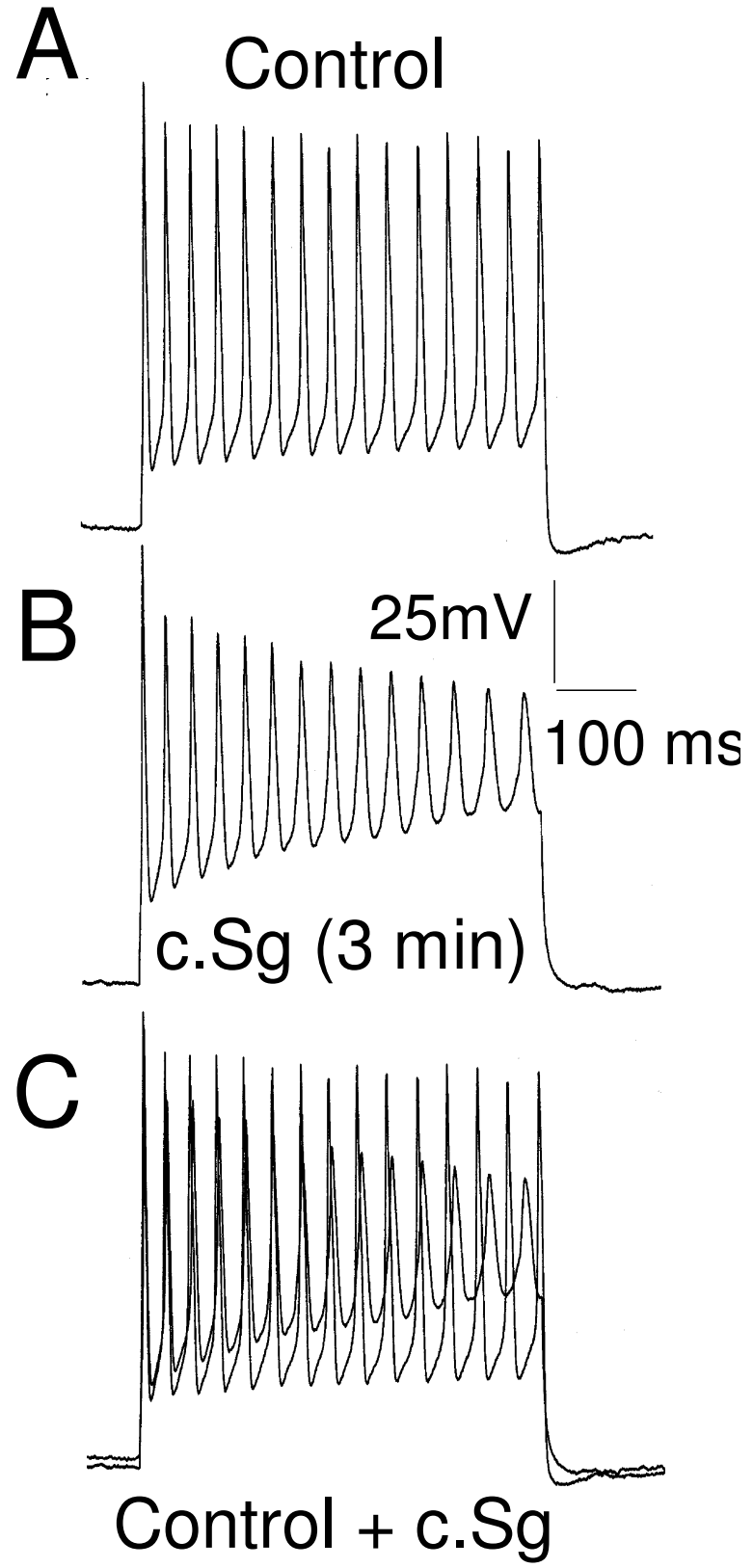

Figure 6

Some DRG neurones under control conditions do not show spike frequency adaptation but fire multiple action potentials during depolarization by 500 ms current commands. This was a different firing pattern to that seen when c.Sg induced multiple fire. A) Voltage trace of control multiple action potential firing neurone. B) Voltage trace of c.Sg-induced multiple firing in the same neurone. $C$ ) Over-plot of voltage traces from $A$ and $B$. In all cases the DRG neurones were held at $-70 \mathrm{mV}$ before stimulation.
The cultured DRG neurones investigated in this study had a mean cell body area of $256 \mu \mathrm{m}^{2}(\mathrm{n}=10$; range 124 to $410 \mu \mathrm{m}^{2}$ ). Responses to c.Sg. were obtained from neurones with different sizes of cell body and different sensitivities to the natural product preparation did not appear to relate to size of cell body.

Similar results were obtained with c.Lobo $(100 \mu \mathrm{g} / \mathrm{mL} ; \mathrm{n}$ $=4$ ). Figure $8 \mathrm{G}$ shows a striking example of enhancement of a KCl-evoked $\mathrm{Ca}^{2+}$ transient in the presence of c.Lobo, but a more complete analysis of this sample was not possible because of the limited amount of material available.

\section{Actions of crude extracts from soft corals on voltage- activated potassium currents in DRG neurones}

The effects of the crude soft coral extracts suggested their action, at least part, involved the inhibition of voltageactivated $\mathrm{K}^{+}$conductances. Specifically, the soft coral samples from Sarcophyton glaucum and Lobophyton crassum prolonged action potentials, attenuated spike frequency adaptation, reduced rectification and enhanced KClevoked $\mathrm{Ca}^{2+}$ transients, all of which could be associated with inhibition of $\mathrm{K}^{+}$currents. DRG neurones express diverse $\mathrm{K}^{+}$channels and in small DRG neurones five types have been identified $\left(\mathrm{A}, \mathrm{DR}_{\mathrm{F}}, \mathrm{DR}_{1}, \mathrm{DR}_{2} \& \mathrm{DR}_{3}\right)$. All these channels play roles in the control of action potential repolarisation and $\mathrm{DR}_{1-3}$ influence action potential firing threshold and after-hyperpolarisation and thus can influence firing patterns [26]. To investigate the actions of the soft coral extracts further, from a holding potential of -70 $\mathrm{mV}$, outward currents were activated by $100 \mathrm{~ms}$ voltage step commands to potentials positive to $-50 \mathrm{mV}$. Three to five minutes application of $100 \mu \mathrm{g} / \mathrm{mL}$ c.Sg significantly inhibited the voltage-activated $\mathrm{K}^{+}$current at all voltages between $-40 \mathrm{mV}$ and $+60 \mathrm{mV}$ (Fig. 9A \&9B).

Control currents were activated fully within $15 \mathrm{~ms}$ and were sustained during $100 \mathrm{~ms}$ depolarizations, but in the presence of c.Sg the currents shape was changed. After 1 minute application of c.Sg the outward currents were reduced and became transient in nature. Partial recovery of the outward current was observed 15 minutes after removal of the perfusion pipette containing c.Sg. Additionally, partial recovery was also associated with a progressive slowing in the current decay during the voltage step command (Fig. 9B).

The actions of c.Lobo on voltage-activated $\mathrm{K}^{+}$currents followed a similar pattern to that seen with c.Sg. Application of $100 \mu \mathrm{g} / \mathrm{mL}$ c.Lobo significantly inhibited the voltageactivated outward current and resulted in a decline in the current during the $100 \mathrm{~ms}$ voltage step command (Fig. 9C \&9D). c.Lobo significantly reduced the outward current at all potentials between $-20 \mathrm{mV}$ and $+90 \mathrm{mV}$. At a clamp potential of $+60 \mathrm{mV}$, under control conditions the mean 


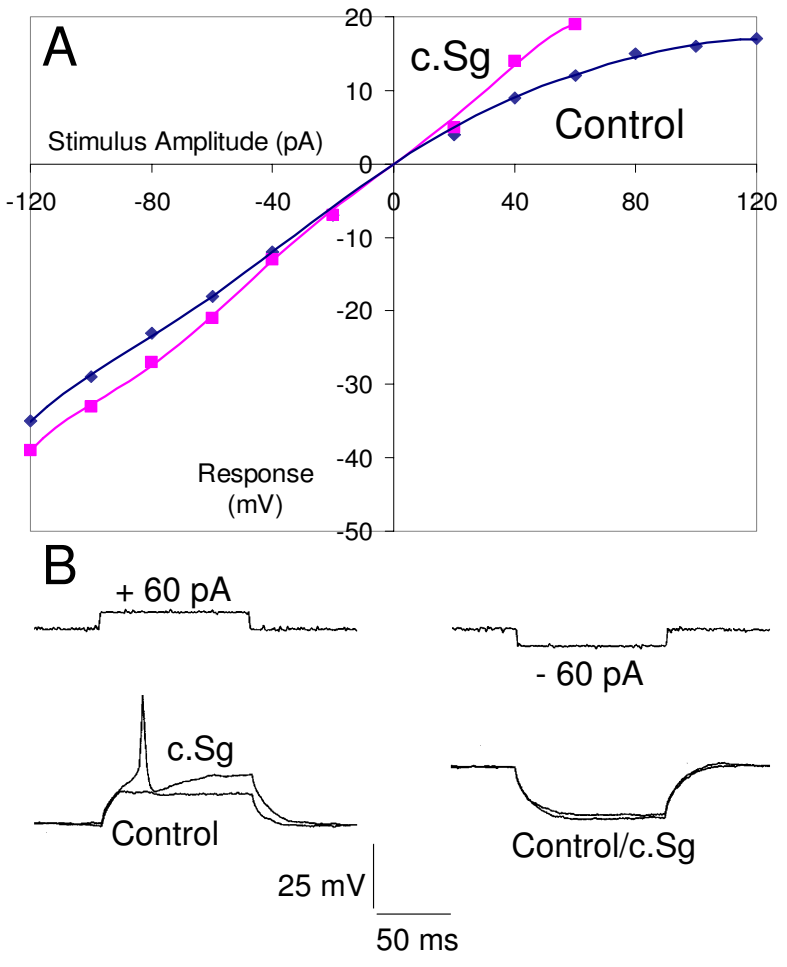

Figure 7

Rectification in DRG neurones is attenuated by c.Sg in DRG neurones. A) Line graph showing voltage-current relationships before (Control blue line) and after the application of c.Sg ( $100 \mu g / \mathrm{mL}$; red line) in the same neurone. B) Traces of current commands $+60 p A$ and $-60 p A$ and voltage responses in cultured DRG neurone before and after the application of c.Sg. In all cases the DRG neurones were held at $-70 \mathrm{mV}$ before stimulation.

peak outward current was $3.8 \pm 0.8 \mathrm{nA}$ and the mean current was significantly reduced to $0.7 \pm 0.12 \mathrm{nA}(\mathrm{n}=6 ; \mathrm{P}<$ 0.005 ) by c.Lobo.

The crude extracts from soft corals did not significantly alter linear leak currents activated between -80 and -140 $\mathrm{mV}$. At $-120 \mathrm{mV}$ the mean leak currents were $-0.026 \pm 0.01$ $\mathrm{nA}$ and $-0.032 \pm 0.01 \mathrm{nA}(\mathrm{n}=9, \mathrm{NS})$ under control conditions and in the presence of soft coral extract respectively.

The changes in shape of the voltage-activated $\mathrm{K}^{+}$currents that were particularly apparent during the development of inhibition produced by both soft coral samples may be indicative of an open channel block mechanism of the active natural product common to both crude extracts.

To investigate the mechanism of inhibition we looked for any effect of the soft coral extracts on steady state inactivation and for evidence of use-dependence during the onset of inhibition by crude soft coral extracts (Figure 10). Steady-state inactivation plots allowed the proportion of voltage-gated channels available to open at any given voltage to be determined. Drug interactions with channels or differential effects of a drug to alter the population of active channels can shift steady-state inactivation plots. Under voltage-clamp conditions neurones were held between -100 and $-10 \mathrm{mV}$. From these holding potentials, neurones were stimulated with voltage step commands to $+30 \mathrm{mV}$ in the absence (control) and presence of $100 \mu \mathrm{g} /$ $\mathrm{mL}$ c. $\mathrm{Sg}(\mathrm{n}=6)$. As can be seen from the raw current data (Fig. 10A) and the normalized plot (Fig. 10B) c. Sg had no significant effects on $\mathrm{K}^{+}$current steady-state inactivation. The mean voltages at which $50 \%$ of the channels were available to open $\left(\mathrm{V}_{0.5 \text { (inact) }}\right)$ were $-50 \pm 2 \mathrm{mV}$ in the control and $-53 \pm 3 \mathrm{mV}(\mathrm{n}=6$; NS) in the presence of $\mathrm{c}$. Sg.

Preliminary results indicate that the delay between command steps has a critical effect on the size of the second response when two pulses are given in succession in the presence of c. Sg. A series of experiments were conducted whereby the delays between pulses were varied $(1,5$ and 10 seconds). A 10 second delays between step commands resulted in recovery of the $\mathrm{K}^{+}$current. In contrast a delay of $1 \mathrm{~s}$ resulted in further decline in the current (Fig. 10C). These data suggest there is a component of use-dependent inhibition but recovery can occur in 5-10 s. We conclude that the slowly developing main component of $\mathrm{K}^{+}$current inhibition produced by the soft coral extracts involves another mechanism.

\section{Actions of purified active compound from Sarcophyton glaucum}

Directed by chemical analysis and biological testing of crude extracts, the common active compound was identified as 3-carboxy-1-methyl pyridinium (trigonelline hydrochloride). This was purified from the crude extracts from Sarcophyton glaucum (p.Sg) and tested using electrophysiological protocols described above. DRG neurones were held at $-70 \mathrm{mV}$ and bathed in extracellular recording medium containing $0.1 \%$ DMSO. Similar to the crude extracts the purified preparation p.Sg (estimated at $30 \mu \mathrm{g} /$ $\mathrm{mL} ; \sim 200 \mu \mathrm{M}$ ) attenuated spike frequency adaptation and three minutes application of pure compound (p.Sg) resulted in multiple action potential firing in response to depolarizing current. This response was reversible but recovery was slow and as seen with the crude samples the effect of the natural product deepened after removal of the drug perfusion pipette (Fig. 11A). Similarly, p.Sg also attenuated the mean peak voltage-active $\mathrm{K}^{+}$currents at +60 $\mathrm{mV}$ by $15 \%(\mathrm{n}=4 ; \mathrm{P}<0.01)$. However, these responses were modest and further inhibition could be obtained with c.Sg (Fig. 11B \&11C). This was in part due to differences in concentrations tested and the small amounts of purified compound available. However, other compo- 

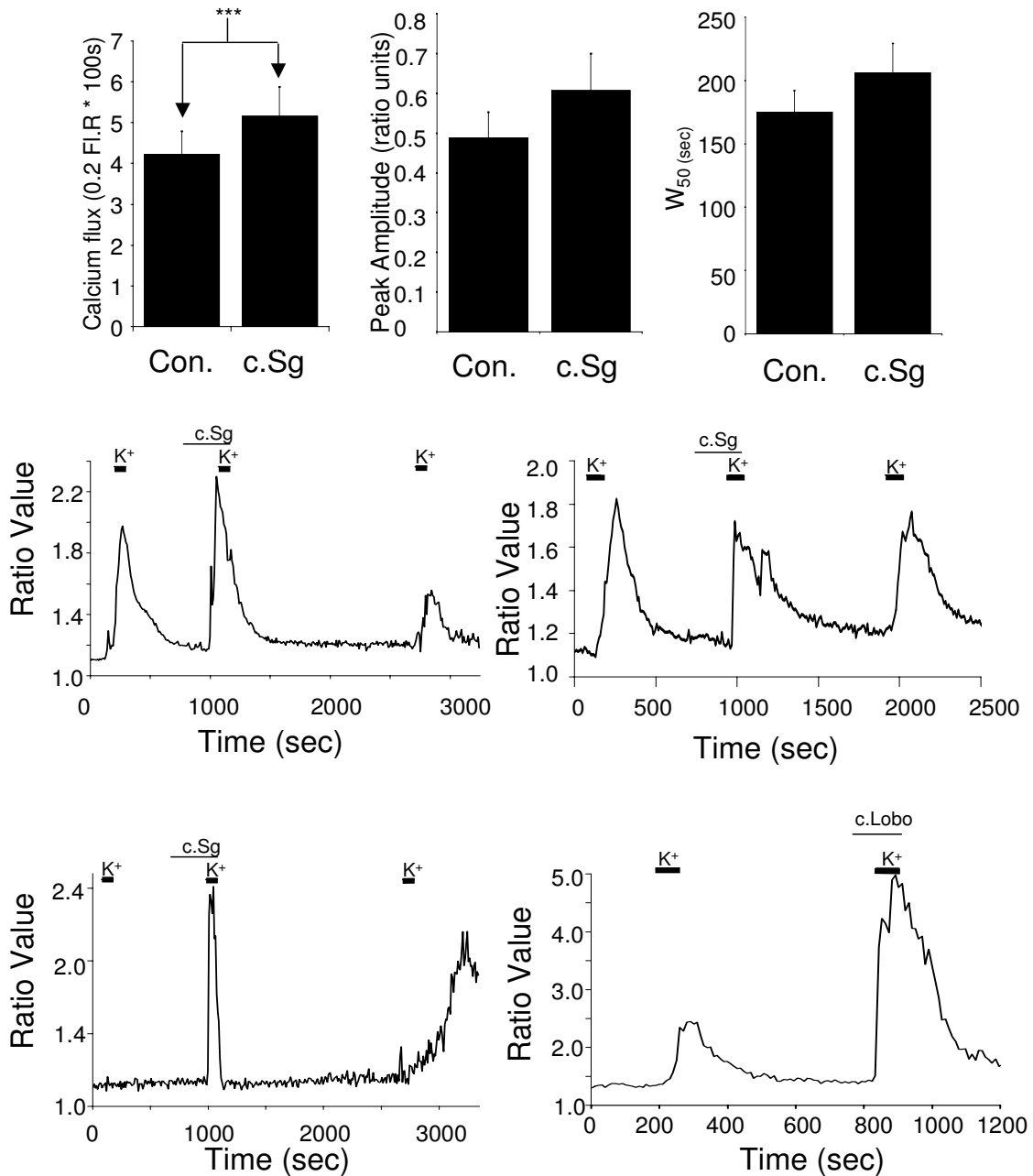

\section{Figure 8}

Application of c.Sg increases $\mathrm{K}^{+}$-evoked calcium flux into cultured DRG neurones. A) Bar chart showing a significant enhancement of the $\mathrm{K}^{+}$-evoked $\mathrm{Ca}^{2+}$ flux induced by c.Sg compared to the control (Con.). B) Bar chart showing mean peak $\mathrm{Ca}^{2+}$ transient amplitudes evoked by $\mathrm{K}^{+}$under control conditions (Con.) and in the presence of c.Sg. C) Bar chart showing mean values for the width $50 \%$ of the $\mathrm{Ca}^{2+}$ transient evoked under control conditions (Con.) and in the presence of c.Sg. For A, B and $\mathrm{C}$ mean values \pm SEM are shown from 17 neurones $(* * * P<0.005)$. D) Example trace of $\mathrm{Ca}^{2+}$ transients showing the increase in amplitude in a single neurone exposed to c.Sg. E) Example trace showing enhancement in $\mathrm{Ca}^{2+}$ transient duration in a single neurone exposed to c.Sg. F) Trace demonstrating that application of c.Sg can cause $\mathrm{K}^{+}$-evoked $\mathrm{Ca}^{2+}$ flux in a neurone that previously showed no $\mathrm{K}^{+}$-evoked $\mathrm{Ca}^{2+}$ flux. G) Example trace showing that c.Lobo has a similar effect to c.Sg. In all traces (D to $\mathrm{G}$ ) the period of stimulation with $\mathrm{KCl}(30 \mathrm{mM})$ is shown by thick bars and the period of application of crude samples from soft corals is shown with thin bars. 


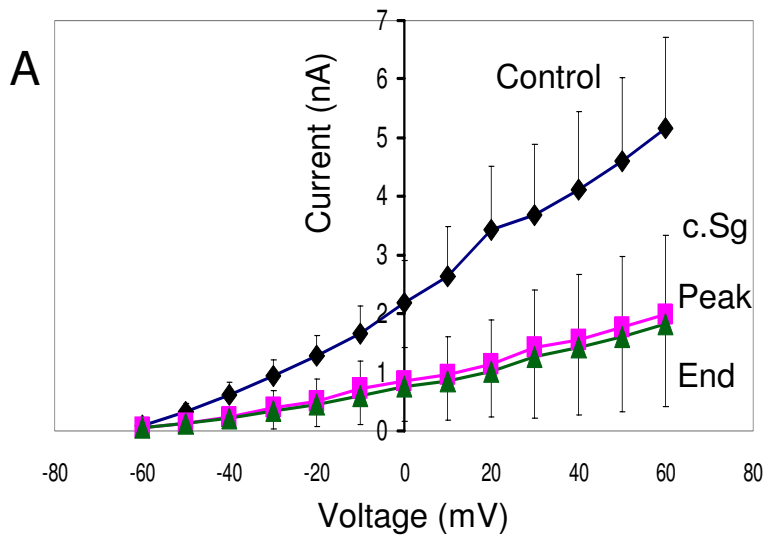

B
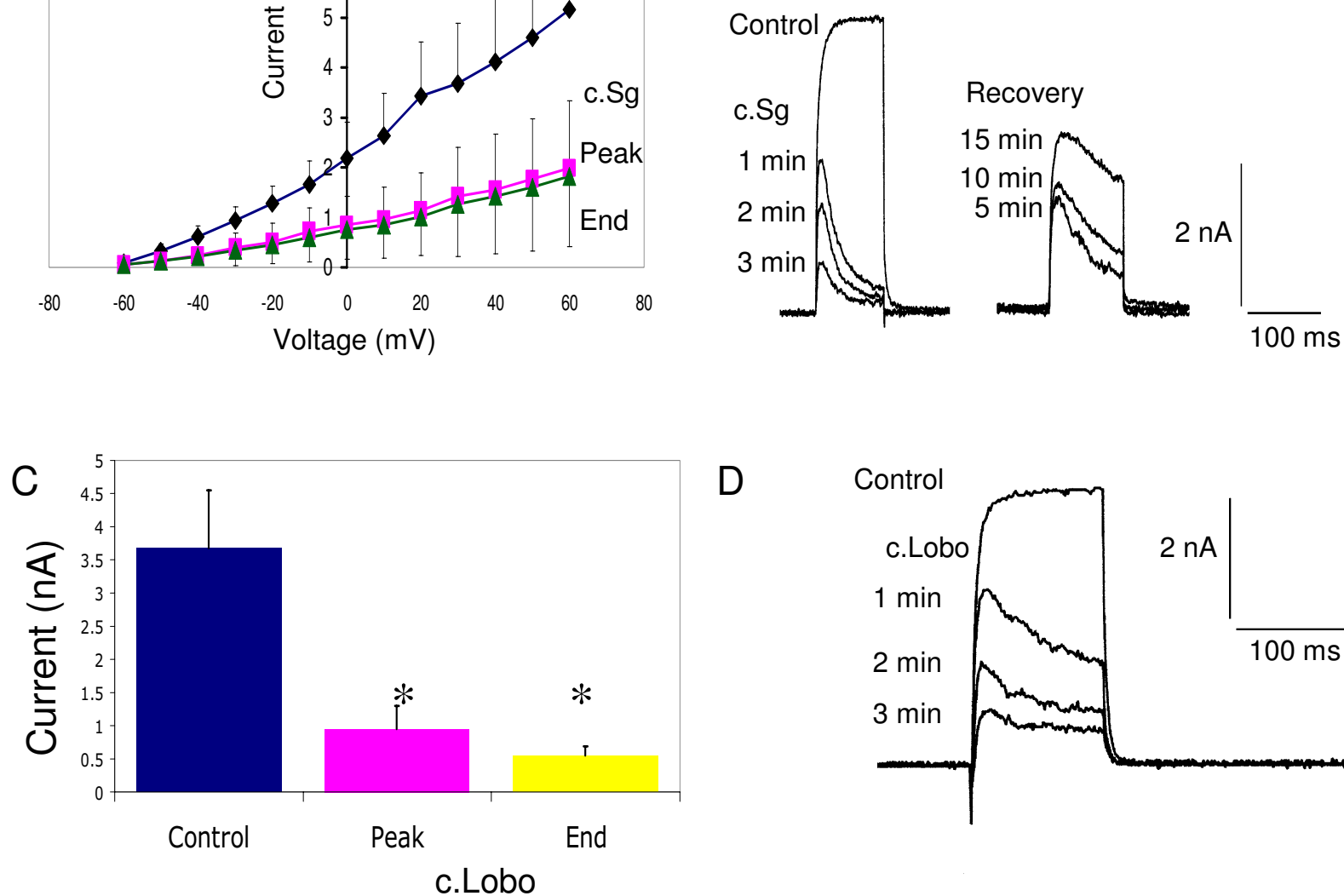

D

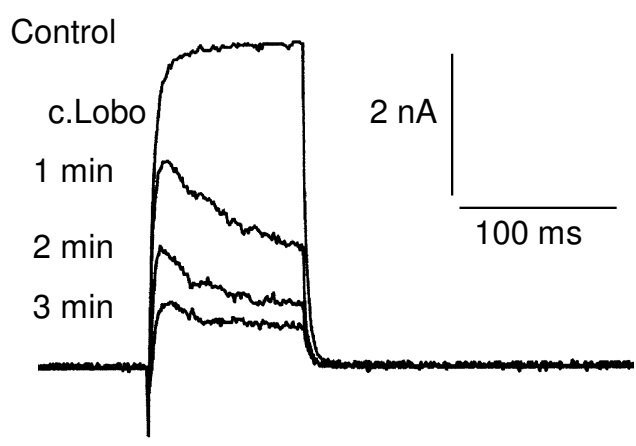

\section{Figure 9}

Whole cell voltage-activated $\mathrm{K}^{+}$currents in cultured DRG neurones are significantly reduced by c.Sg or c.Lobo (I00 $\mu$ g $\left./ \mathrm{mL}\right)$. A) Line graph showing mean $( \pm$ sem) current-voltage relationships under control conditions (blue line) and after the application of c.Sg (red and green lines). The current amplitudes measured at the peak (red) and at the end of the voltage step command (green) are illustrated. B) Net $\mathrm{K}^{+}$current traces showing the onset of the inhibitory effects of c.Sg and the time course of partial recovery. The neurone was voltage clamped at $-70 \mathrm{mV}$ and currents were evoked by voltage step commands to $+60 \mathrm{mV}$. C) Bar chart illustrating mean current amplitudes $(n=6$; $* p<0.02)$ at $+60 \mathrm{mV}$, under control conditions (blue bar), the peak current in the presence of c.Lobo (red bar) and the current recorded at the end of a 100 ms voltage step command in the presence of c.Lobo (yellow bar). D) Net $\mathrm{K}^{+}$current traces showing the development of current inhibition by c.Lobo. The neurone was voltage clamped at $-70 \mathrm{mV}$ and currents were evoked by voltage step commands to $+60 \mathrm{mV}$.

nents within the crude extract may enhance the activity of the major active component from Sarcophyton glaucum.

\section{An investigation of the possible roles of intracellular signalling in the bioactivity of crude extracts from Sarcophyton glaucum}

Slow onset of the responses to the crude extracts from Sarcophyton glaucum and Lobophyton crassum, the continued development of their effects after it was no longer being applied, and the slow recovery phase all raised the possibility that modulation of neuronal excitability might involve the activation of intracellular signals rather than a direct interaction with $\mathrm{K}^{+}$channels. To investigate this possibility, three approaches were taken to disrupt certain intracellular signalling which might modulate $\mathrm{K}^{+}$channels. Firstly, the cyclooxygenase 1 and 2 inhibitor indomethacine $(10 \mu \mathrm{M})$ was applied to the bath and to the intracellular environment via the patch pipette solution. The activities of cyclooxygenases have been implicated in modulating $\mathrm{K}^{+}$conductances to increase neuronal excitability $[27,28]$. Secondly, pertussis toxin sensitive Gproteins were inhibited by incubating the DRG neurones for 18 hours with $500 \mathrm{ng} / \mathrm{mL}$ pertussis toxin. Thirdly, the protein kinase $\mathrm{C}$ inhibitor chelerythrine ( $3 \mu \mathrm{M}$; [29]) was applied to the intracellular environment via the patch pipette solution. At a concentration of $100 \mu \mathrm{g} / \mathrm{mL}, \mathrm{c} . \mathrm{Sg}$ 

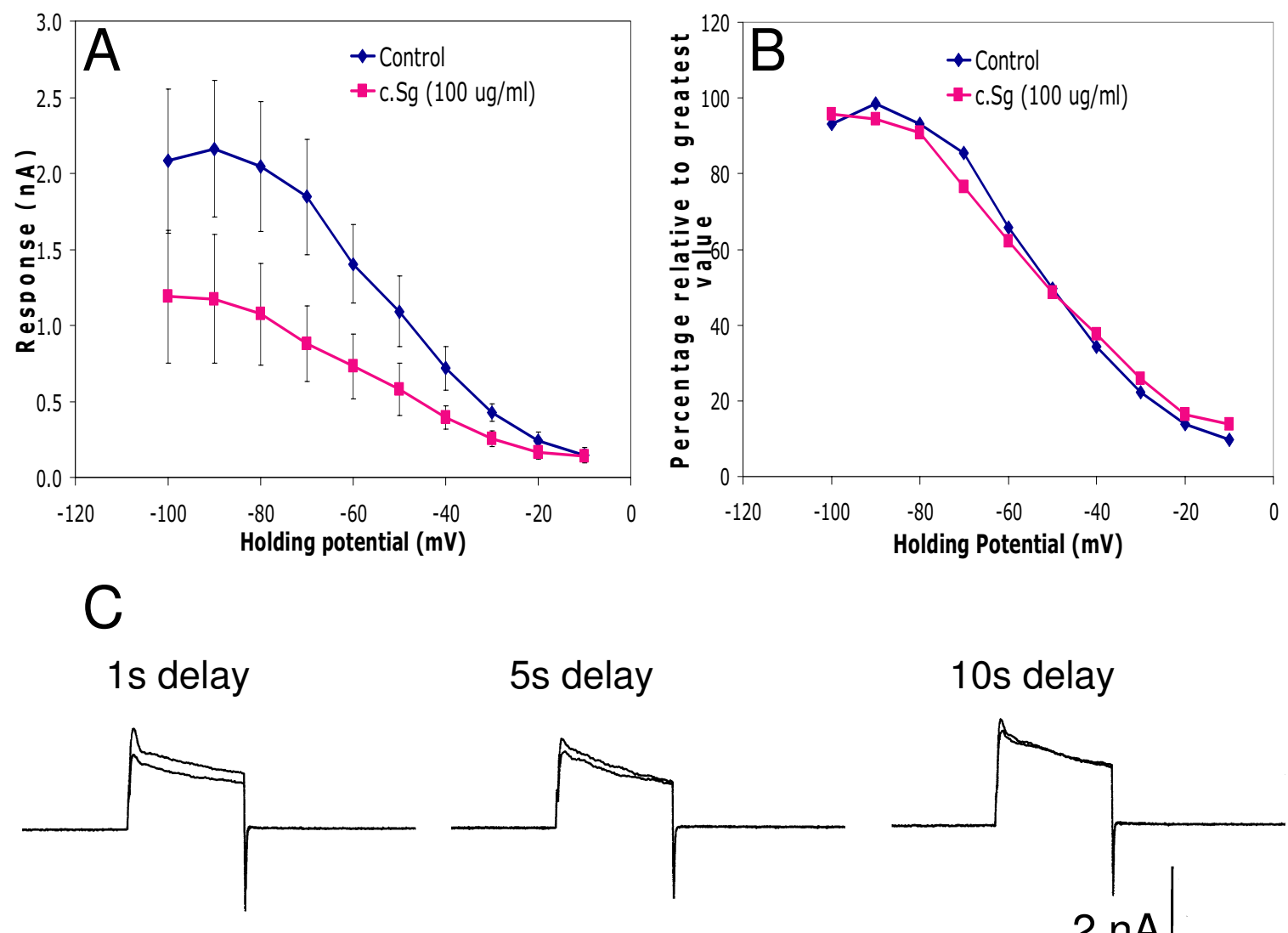
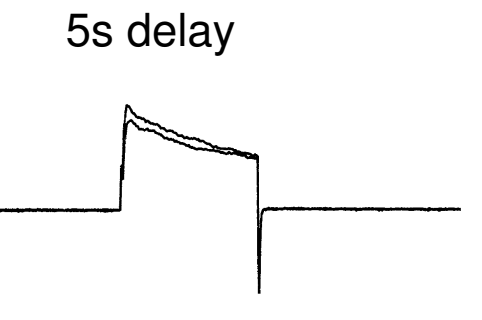

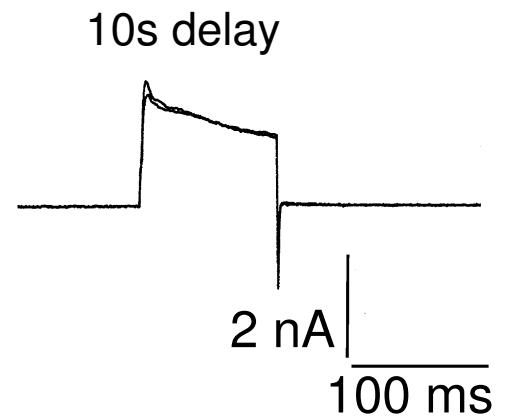

\section{Figure 10}

Extract from Sarcophyton glaucum $(100 \mu \mathrm{g} / \mathrm{mL})$ did not cause a change in steady state inactivation but does show some activity dependence. A) Line graph showing mean control steady state currents ( \pm s.e.m) activated from holding potentials between 100 and $-10 \mathrm{mV}$ by voltage step commands to $+30 \mathrm{mV}$ (blue) and the steady state inactivation relationship after application of c.Sg $(n=6)$. B) Line graph showing the normalised mean steady state inactivation plots under control conditions (blue) and after the application of c.Sg $(n=6)$. For each plot the current values were normalized with respect to the maximum outward current. C) The effect of a I s, $5 \mathrm{~s}$ and $10 \mathrm{~s}$ delays between concurrent voltage step commands on the net $\mathrm{K}^{+}$outward current (at $+30 \mathrm{mV})$ during application of c. Sg $(100 \mu \mathrm{g} / \mathrm{mL})$.

persisted in enhancing DRG neurone excitability in the presence of indomethacine, after pertussis toxin pre-treatment and in the presence of chelerythrine. Spike frequency adaptation was attenuated and multiple firing was observed under all three conditions (Fig. 12A,B, \&12C). Additionally, as previously observed in the absence of blockers c.Sg inhibited voltage-activated $\mathrm{K}^{+}$currents in the presence of indomethacin $(\mathrm{n}=2$; Fig. 12D), after pertussis toxin treatment $(\mathrm{n}=3$; Fig. 12E) and in the presence of chelerythrine ( $\mathrm{n}=3$; Fig. 12F). Although not an exhaustive list of potential target sites, our data clearly indicates that the soft coral natural product does not enhance excitability through cyclooxygenases, activation of a pertussis toxin G-protein or via protein kinase C.

\section{Actions of 3-carboxy-I-methyl pyridinium on cultured DRG neurones}

The identification of 3-carboxyl-1-methyl pyridinium (CPM) as an active component in samples from Sarcophyton glaucum and Lobophyton crassum but not Sinularia leptoclados resulted in testing a synthetic sample of this compound. In our initial studies, we applied CPM in the presence of $0.1 \%$ DMSO to keep the recording conditions the same as with the soft coral extracts. Tests were also conducted in the absence of DMSO and it was found that the presence or absence of DMSO had no bearing on the results. Although $100 \mu \mathrm{M}$ CPM attenuated spike frequency adaptation and induced multiple firing (Fig. 13A \&13B), some features of the biological activity seen with 

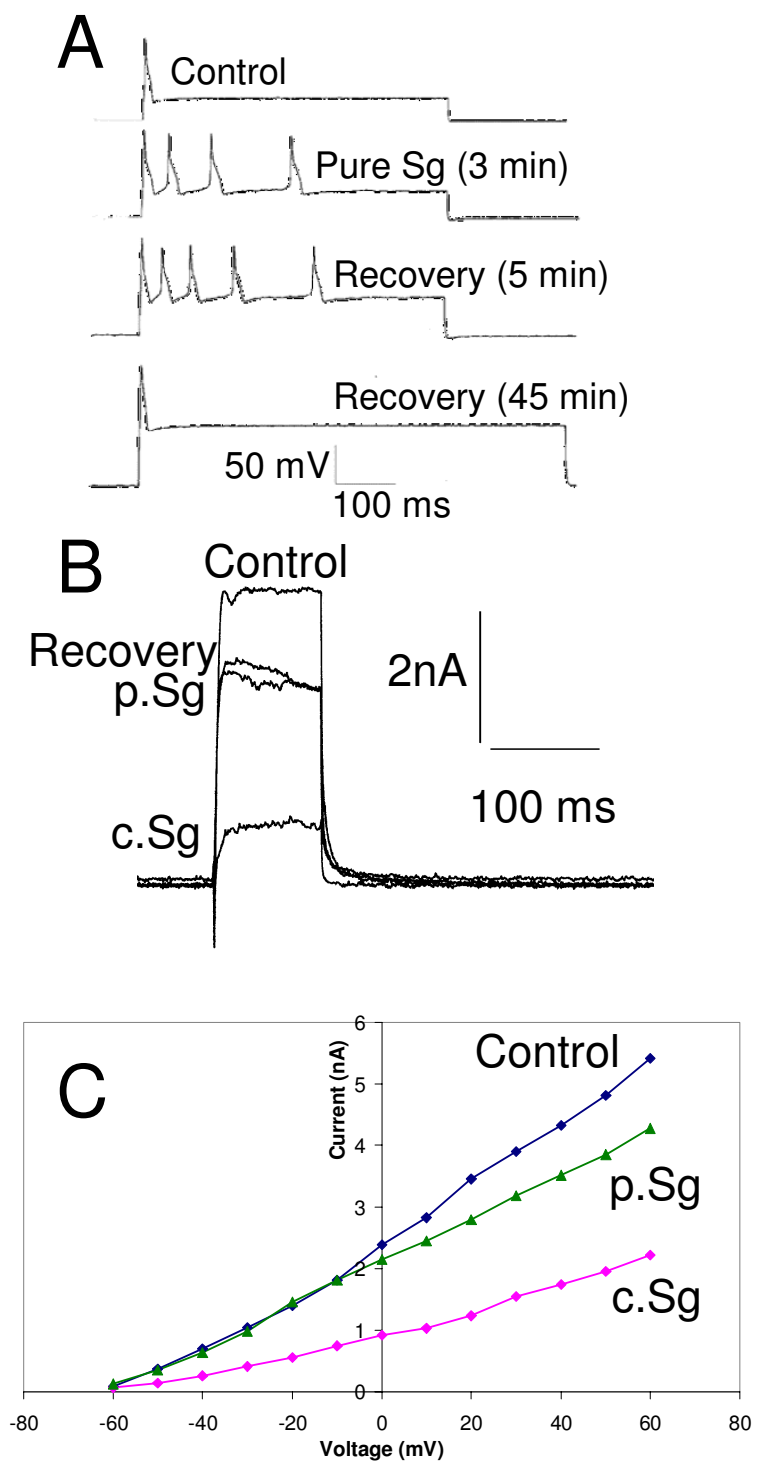

\section{Figure I I}

A purified sample from Sarcophyton glaucum (p.Sg) increased excitability and attenuated voltage-activated $\mathrm{K}^{+}$currents in cultured DRG neurones. A) Example of voltage traces showing reversible inhibition of spike frequency adaptation and the development of multiple action potential firing by p.Sg $(\sim 10$ $\mu \mathrm{M})$. B) Voltage-clamp current traces showing the inhibitory effects of c.Sg ( $100 \mu \mathrm{g} / \mathrm{mL})$ and p.Sg $(30 \mu \mathrm{g} / \mathrm{mL} ; 200 \mu \mathrm{M})$ on DRG neurones held at $-70 \mathrm{mV}$ and depolarized to $+60 \mathrm{mV}$ by voltage step commands. Partial recovery of the net $\mathrm{K}^{+}$current was seen after 10 mins. C) Line graph showing the current-voltage relationships under control conditions (blue line), after application of p.Sg (30 $\mu \mathrm{g} / \mathrm{mL} ; ~ 200 \mu \mathrm{M}$; green line) and then c.Sg ( $100 \mu \mathrm{g} / \mathrm{mL}$; red line) recorded from a single DRG neurone. the natural product samples were not seen with the synthetic compound. These included action potential prolongation and depolarizing drift in the electrotonic potential. This may be explained by the lower level of $\mathrm{K}^{+}$current inhibition seen with $100 \mu \mathrm{M}$ CPM compared with $100 \mu \mathrm{g} /$ $\mathrm{mL}$ crude sample. In the presence and absence of $0.1 \%$ DMSO, CMP inhibited the $\mathrm{K}^{+}$current at $+60 \mathrm{mV}$ by $51 \pm 9$ $\%(n=6)$ and $42 \pm 13 \%(n=5 ;$ Fig. 13C \&13D). These data suggest that DMSO is not a factor in determining the actions of CPM. Raising the concentration of CPM to 1 $\mathrm{mM}$ resulted in greater inhibition of the $\mathrm{K}^{+}$current at +60 $\mathrm{mV}$ to $82 \%$. This compares with the level of inhibition of $90 \%$ produced by $100 \mu \mathrm{g} / \mathrm{mL}$ of crude sample. From this we conclude that enhanced excitability of DRG neurones was caused by CPM, which is a major component in the crude samples from Sarcophyton glaucum and Lobophyton crassum. We estimate that the soft coral extract contained $\sim 7 \%$ CPM, which would give approximately $50 \mu \mathrm{M}$ CPM in the test dose of $100 \mu \mathrm{g} / \mathrm{mL}$. Clearly there is an apparent anomaly between the time courses of the currents and amplitude of the responses observed when the actions of the soft coral samples and CPM from a synthetic source are compared. This discrepancy is not due to the presence of DMSO and would appear to result from an additional as yet unidentified natural product or products present in the samples. These other substances may enhance delivery and/or action of CPM.

\section{Conclusion}

The crude samples from Sarcophyton glaucum and Lobophyton crassum but not Sinularia leptoclados gave NMR spectra that had common peaks in the region 7-9 ppm. The presence of a common natural product in two species of soft coral but not a third may result from biosynthesis in soft coral tissues but could also be the result of metabolism in symbiotic organisms common to Sarcophyton glaucum and Lobophyton crassum. However, all three species studied have symbiotic Zooxanthellae and the biosynthesis of CPM may reflect common ancestry. The optimum defense theory predicts that organisms with any sort of mechanical defense will not be vulnerable to predators and consequently lack chemical defenses. Thus, we suggest that Sinularia that is heavily encrusted and is highly packed with dense spicules does not produce CPM: while the fleshy flourishing Lobophyton and Sarcophyton samples produce defences that might include CPM for protection. Phylum Cnidaria, that include soft corals, may gain a level of defence from potential vertebrate predators by increasing excitability and producing abnormal firing patterns in sensory neurones. In certain Hydrozoa, relatively low concentrations of trigonelline $(0.1-10 \mu \mathrm{M} ; 20$ hours $)$ antagonised larval metamorphosis induced by $\mathrm{Cs}^{+}$enriched seawater [30]. It is not clear if there is any relationship between the chemical control of development and chem- 


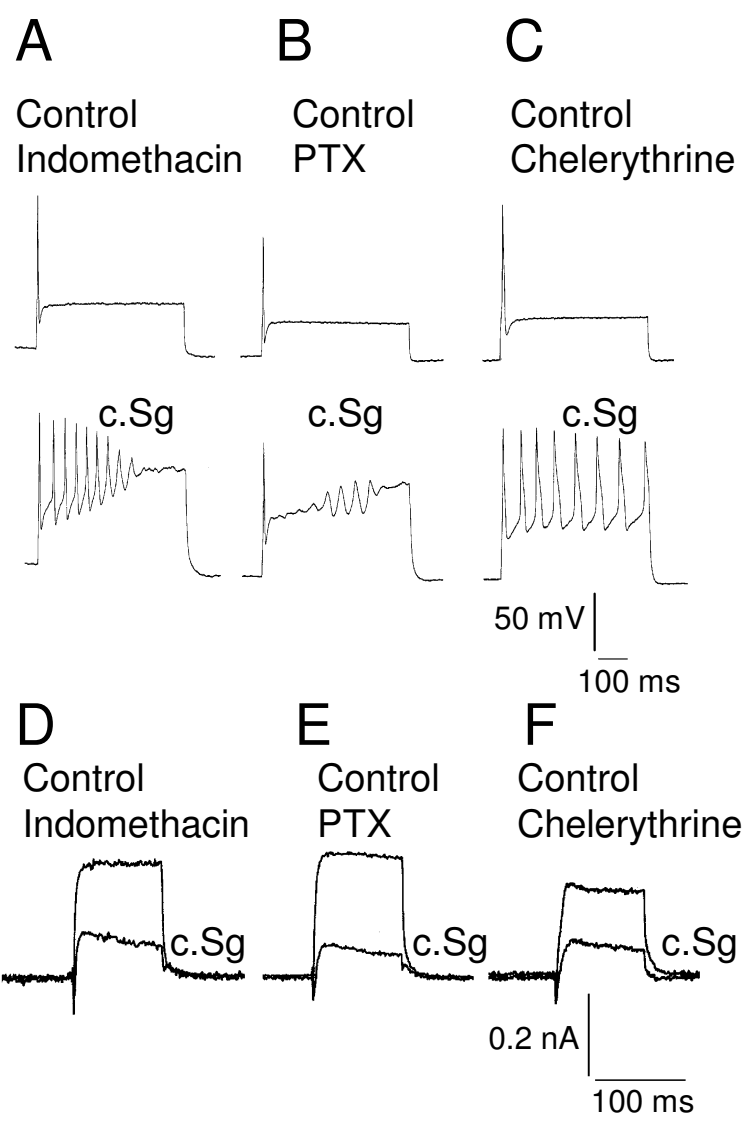

Figure 12

Actions of c.Sg are not inhibited by indomethacin, pertussis toxin pre-treatment or chelerythrine. A, B \& C) Voltage records showing action potential firing properties in the presence of the three test treatments (indomethacin, pertussis toxin pre-treatment or chelerythrine) and multiple action potential firing evoked by $100 \mu \mathrm{g} / \mathrm{mL}$ c.Sg. Indomethacin (A) pertussis toxin pretreatment $(B)$ and chelerythrine $(C)$ all failed to prevent the switch to multiple firing after application of c.Sg to DRG neurones that previously fired single action potentials. At rest all neurones were held at $-70 \mathrm{mV}$. D, E \& F) Current traces illustrating voltage-activated $\mathrm{K}^{+}$current activated at $+60 \mathrm{mV}$ by 100 ms voltage step commands from a holding potential of $-70 \mathrm{mV}$. In the presence of the three test treatments (indomethacin, pertussis toxin pre-treatment or chelerythrine) c.Sg still induced multiple action potential firing and attenuated the voltage-activated $\mathrm{K}^{+}$currents.

ical defence potentially provided (albeit at significantly higher concentrations) by the same compound.

Pyridinium compounds represent a biosynthetic starting point for pore forming alkylpyridinium chemical defences found in marine sponges $[6-9,31]$. They may also provide interesting evolutionary links or offer evidence for common symbiotic relationships between distinct organisms that have different chemical defences based around pyridinium salts.

The alkaloid CPM is not a novel compound and has a fairly wide distribution in the plant and animal kingdoms. It has been identified in a number of higher plant species [32] and in marine shellfish [33]. CPM acts as an osmoregulator in plants when they are exposed to excess salts, a function it may also have in some marine invertebrates. It also acts as a cell cycle regulator during the early growth of many legume root meristems [34]. In 1999, Tohda and colleagues [35] reported that CPM induced neurite outgrowth in human neuroblastoma cells, an activity that may be associated with electrophysiological changes and increased excitability.

Potassium channels are a highly diverse group of channels and are targets for a wide range of natural toxins from both marine and terrestrial organisms. Examples of toxins from marine invertebrates that inhibit voltage-activated $\mathrm{K}^{+}$conductances include sea anemone peptides (blood depressing substance BDS-I \& II) [36,37], the coneshell toxin $\kappa$-conotoxin PVIIA [38] and latrunculin A from sponges and nudibranchs [39]. We have not assessed the selectivity of CPM for voltage-activated $\mathrm{K}^{+}$channel subtypes in DRG neurones for two reasons. Firstly, unlike many of the peptide toxins, CPM is not very potent. Secondly, DRG neurones are a heterogeneous population of neurones that express at least six different types of $\mathrm{K}^{+}$ channels in distinct manners [40] and therefore would not provide a suitable assay preparation. Application of CPM increases electrophysiological excitability of DRG neurones. We predict from our study that it is a major component of the soft coral extracts that is responsible for changes in current kinetics and the inhibition of delayed rectifier $\mathrm{K}^{+}$channels. Additionally, CPM increases $\mathrm{KCl}$ evoked $\mathrm{Ca}^{2+}$ flux an action consistent with an increase in action potential firing. However, the intracellular $\mathrm{Ca}^{2+}$ signals in part result from $\mathrm{Ca}^{2+}$-induced $\mathrm{Ca}^{2+}$ release from intracellular stores and $\mathrm{Ca}^{2+}$ release channels may also be modulated by CPM. Furthermore, altering the patterns of action potential firing in sensory neurones may provide mechanisms for chemical defence. The actions of the natural products and CPM was not restricted to a subpopulation of small diameter (C-fibre) neurones so a variety of sensory neurones may be effected.

\section{Methods}

\section{Marine sample collection}

Samples were collected from North of Sharm El-Sheikh, Egypt with the following coordinates $\left(28^{\circ} 07^{\prime} 34^{\prime \prime} \mathrm{N}\right.$ and $34^{\circ} 26^{\prime} 28^{\prime \prime}$ E). Field observations were carried out by scuba diving. Underwater ecological observations of the reef profile where collections were recorded [41]. The per- 


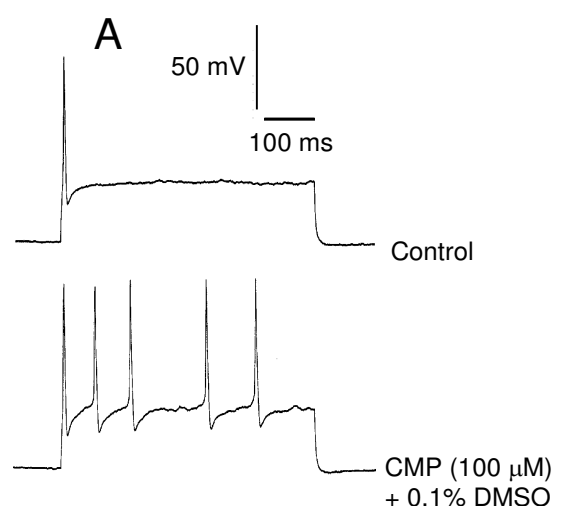

B
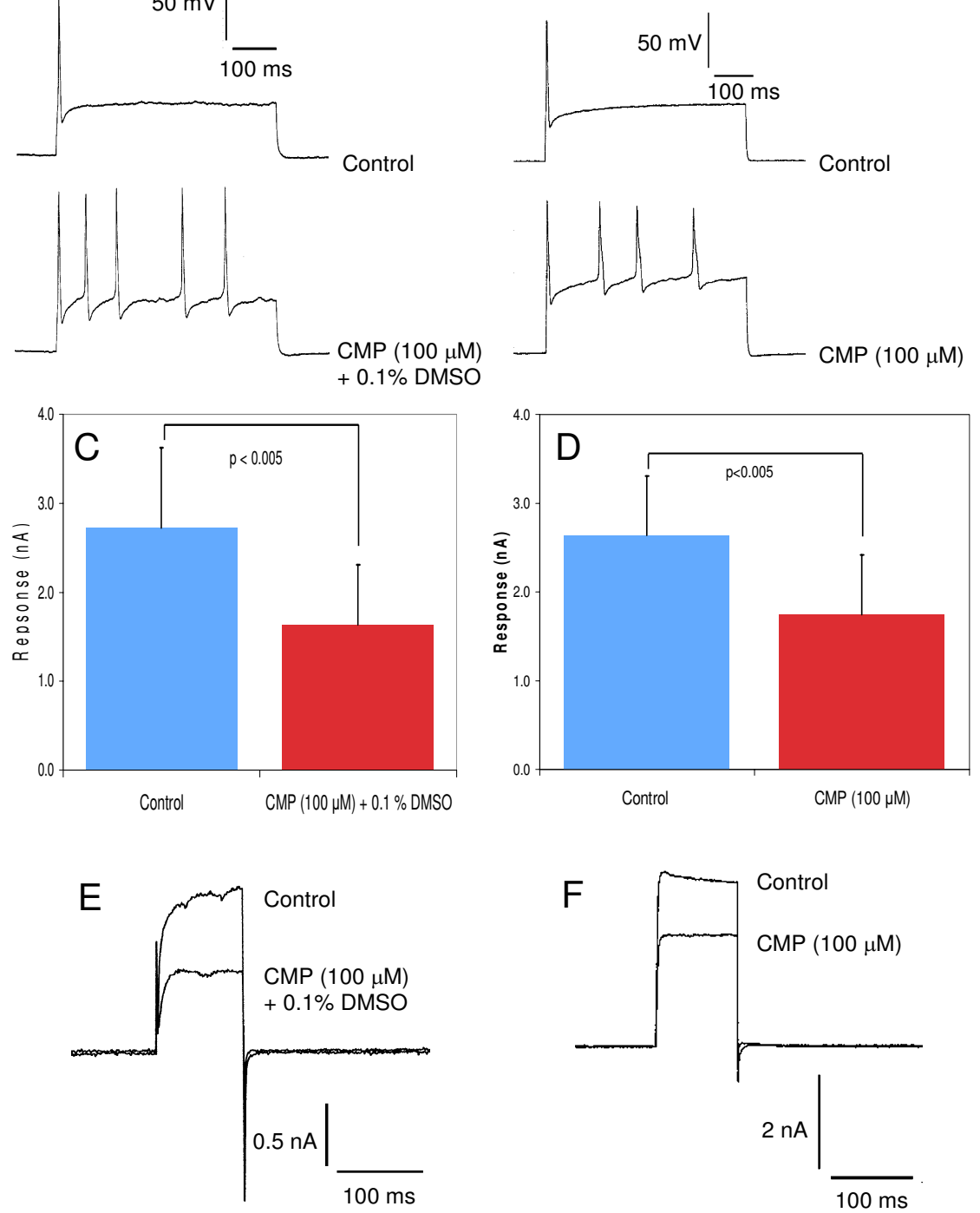

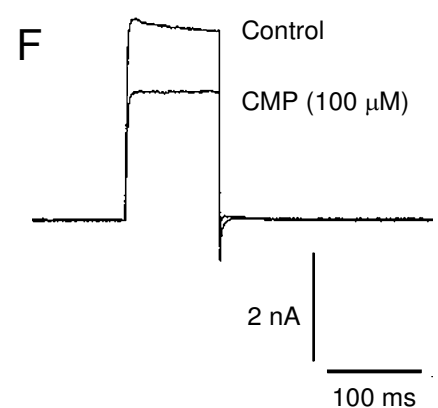

\section{Figure 13}

The presence or absence of DMSO has no effect on the actions of synthetic 3-carboxy-I-methyl pyridinium (CMP) on DRG neurones. A) Records of action potentials showing single action potential firing under control conditions and multiple firing induced by CMP (I00 $\mu \mathrm{M})$ in the presence of $0.1 \%$ DMSO. B) Records of action potentials showing single action potential firing under control conditions and multiple firing induced by CMP $(100 \mu \mathrm{M})$ in the absence of DMSO. At rest both neurones were held at $-70 \mathrm{mV} \mathrm{C}$ ) Bar chart showing the significant decrease in the mean voltage-activated $\mathrm{K}^{+}$current (holding potential -70 $\mathrm{mV}$, clamp potential for current activation $+60 \mathrm{mV})$ evoked by CMP $(100 \mu \mathrm{M})$ in the presence of $0.1 \% \mathrm{DMSO}$. D) Bar chart showing the significant decrease in the mean voltage-activated $\mathrm{K}^{+}$current (holding potential $-70 \mathrm{mV}$, clamp potential for current activation $+60 \mathrm{mV})$ evoked by CMP $(100 \mu \mathrm{M})$ in the absence of DMSO. E \& F) Current traces under voltage clamp showing the decrease in $\mathrm{K}^{+}$current produced by CMP. 
centage cover of the different substrates in the study area were estimated using line intercept transects and the percentage cover of each taxon was calculated. Substrate components were classified as hard corals, soft corals, dead corals (recognized by over growing algae), and others including plants (filamentous algae, calcareous algae, fleshly algae), associated fauna (molluscs, echinoderms and sponges), in addition to the 'dead substrate' component (sand and rock).

Directly after collection, the samples (60-70 g) were rinsed thoroughly in seawater and placed on ice for transfer to the laboratory and kept at $-20^{\circ} \mathrm{C}$ until extraction. Each sample was split into two parts, one part (50 g) was used for the extraction and a second longitudinal section was used for the species identification.

Multiple extraction was done over three days using a mixture of 1:1 (v:v) methanol and dichloromethane. Following extraction at room temperature, under dark conditions the extracts were concentrated under reduced pressure to yield $459 \mathrm{mg}$ of Sarcophyton extract.

Soft coral identification was accomplished by bleaching the tissue to remove debris and isolate the spicules. Morphological measurements and spicule examination were the key factors in identification [42].

Three species of soft corals were collected namely (Sarcophyton glaucum, Sinularia leptoclados and Lobophyton crassum). Voucher specimens are kept at the museum of the Marine Science Department at SuezCanal University and their index numbers are:

MSD OCT 10422 for Sarcophyton sample

MSD OCT 10442for Sinularia sample

MSD OCT 10452 for Lobophyton sample

\section{Chemical identification}

UV spectra were measured on a Perkin-Elmer Lambda 15 $\mathrm{UV} / \mathrm{Vis}$ spectrometer. ${ }^{1} \mathrm{H},{ }^{13} \mathrm{C}$ and all $2 \mathrm{D}$ NMR experiments were recorded on a Varian Unity INOVA $400 \mathrm{MHz}$ spectrometer, in $\mathrm{CD}_{3} \mathrm{OD}\left({ }^{1} \mathrm{H}\right.$ at $400 \mathrm{MHz}$ and ${ }^{13} \mathrm{C}$ at 100 $\mathrm{MHz}$ ). A low-resolution electron ionisation mass spectrum was obtained using a Micromass Quattro II, and high-resolution mass data were obtained on a Finnigan MAT 95 XP. HPLC separations were carried out on a Phenomenex ${ }^{\circledast}$ column $(10 \times 250 \mathrm{~mm}, \mathrm{RP}-\mathrm{C} 18,5 \mu \mathrm{m}$ particle size) connected to an Agilent 1100 series binary pump and monitored using an Agilent photodiode array detector. Detection was carried out at 226, 264 and $320 \mathrm{~nm}$. An authentic sample of 3-carboxy-1-methyl pyridinium (trig- onelline hydrochloride) was purchased from Sigma Chemical Company (Dorset, UK).

Crude organic extracts of Sarcophyton glaucum and Lobophyton crassum were shipped to our laboratory at the University of Aberdeen for biological and chemical investigation and stored at $-20^{\circ} \mathrm{C}$ until used. The close similarity of the ${ }^{1} \mathrm{H}$ NMR spectra of both extracts especially in the region of $\delta_{\mathrm{H}} 7-10$ indicated the presence of at least one common constituent. Electrophysiological experiments showed that both extracts had the same effects on the electrophysiological actions on the cultured DRG sensory neurones from neonatal rats. This indicated that their common constituent(s) might be the responsible for such biological activity. NMR-, TLC- and biologically-guided fractionation of the crude extract of Sarcophyton glaucum was conducted to isolate such biologically active component(s). The crude extract was fractionated by reversed phase HPLC using a mixture of $\mathrm{MeOH}$, water and TFA (80:20:0.05) as eluent. Fractions that showed the characteristic ${ }^{1} \mathrm{H}$ NMR peaks of the common constituent in the region of $\delta_{\mathrm{H}} 7-10$ were pooled together, concentrated under reduced pressure and subjected to an HPLC using a linear gradient of $\mathrm{MeOH}(40-80 \%$ in 20 $\mathrm{min}$ ) in water at a flow rate of $2 \mathrm{~mL} / \mathrm{min}$. Further purification was carried out on the same HPLC column using two solvents: water (A) and methanol (B); starting with $0 \%$ $\mathrm{MeOH}$ and increasing to $10 \% \mathrm{~B}$ at $10 \mathrm{~min}$ and $15 \% \mathrm{~B}$ at $15 \mathrm{~min}$ with a flow rate of $2 \mathrm{~mL} / \mathrm{min}$. More purification was carried out using the same HPLC column with $100 \%$ water as eluent and a flow rate of $1 \mathrm{~mL} / \mathrm{min}$. Final purification was carried out using $0.1 \%$ TFA in water as eluent with a flow rate of $1 \mathrm{~mL} / \mathrm{min}$ to afford $32 \mathrm{mg}$ of 3-carboxy1-methyl pyridinium.

The structure of 3-carboxy-1-methyl pyridinium was elucidated by a combination of NMR techniques, exact mass spectral determination, and comparison with the NMR data of related compounds in the literature.

\section{DRG neuron culture}

Two-day old rats were decapitated and dorsal root ganglia were removed. DRG neurones were dissociated enzymatically $(0.125 \%$ collagenase for 13 minutes and $0.25 \%$ trypsin for 6 minutes) and mechanically (trituration). Primary cultures of DRG neurones were plated on lamininpolyornithine coated coverslips and bathed in Ham's F-14 culture medium (Imperial Laboratories) containing horse serum (10\%; Gibco), NGF (20 ng/mL; Sigma), $\mathrm{NaHCO}_{3}$ (14 $\mathrm{mM})$, streptomycin $(5000 \mu \mathrm{g} / \mathrm{mL})$ and penicillin (5000 IU/mL). The cultures were maintained for up to two weeks at $37^{\circ} \mathrm{C}$ in humidified air with $5 \% \mathrm{CO}_{2}$. Cultures were re-fed with fresh media after 5 days. 
In one set of experiments, the DRG neurone cultures were pre-treated with pertussis toxin $(500 \mathrm{ng} / \mathrm{mL}$; for 18 hours $)$ to ADP-ribosylate the $\alpha$-subunits of certain G-proteins. This prevents pertussis toxin-sensitive G-protein being activated through a range of G-protein coupled receptors and potential effectors involved in increasing neuronal excitability [43].

\section{Patch clamp electrophysiology}

The whole cell patch clamp recording method was used to investigate the actions of soft coral preparations on action potential firing and $\mathrm{K}^{+}$voltage-activated curents. DRG neurone cultures were studied using a patch pipette filling solution containing in $\mathrm{mM}: \mathrm{KCl}, 140$; EGTA, $5 ; \mathrm{CaCl}_{2}, 0.1$; $\mathrm{MgCl}_{2}, 2.0$; HEPES, 10.0; ATP, 2.0. The $\mathrm{pH}$ and osmolarity of the patch pipette solutions were corrected to 7.2 and 310-320 mOsm. $\mathrm{L}^{-1}$ with Tris and sucrose respectively. The $\mathrm{NaCl}$-based extracellular solution containing in $\mathrm{mM}$ : $\mathrm{NaCl}, 130 ; \mathrm{KCl}, 3.0 ; \mathrm{CaCl}_{2} 2.0 ; \mathrm{MgCl}_{2}, 0.6 ; \mathrm{NaHCO}_{3}$ 1.0, HEPES 10.0 glucose 5.0 and $0.1 \%$ DMSO. The $\mathrm{pH}$ and osmolarity of this extracellular bathing solution was corrected to 7.4 and $320 \mathrm{mOsmL}^{-1}$ with $\mathrm{NaOH}$ and sucrose respectively. The soft coral extracts were dissolved in DMSO (equivalent to $100 \mathrm{mg} / \mathrm{mL}$ ). From these stock solutions, the test solutions were made up by dilution with extracellular solution so that they contained $0.1 \%$ DMSO. This concentration of DMSO vehicle will influence the electrophysiological properties of DRG neurones [44]. All experiments were conducted in the presence of $0.1 \%$ DMSO so that the actions of soft coral preparations could be assessed independently of the vehicle. Samples were applied to the extracellular environment by lowpressure ejection from a blunt pipette positioned about $50-100 \mu \mathrm{m}$ away from the cell being recorded. This method allows a stable concentration of drug around a neurone to be achieved within $\sim 10 \mathrm{~s}$. For a series of experiments indomethacine $(10 \mu \mathrm{M} ; 0.01 \%$ ethanol) or chelerythrine $(3 \mu \mathrm{M})$ was applied extracellularly in the bathing solution and intracellularly via the patch pipette solution. After measurement of membrane potential, neurones were held at $-70 \mathrm{mV}$ with constant current injection and electrotonic potentials and action potentials were activated from this voltage.

All voltage-activated $\mathrm{K}^{+}$currents had scaled linear leakage and capacitance currents subtracted to obtain values for the net outward $\mathrm{K}^{+}$current. Data are given as mean \pm standard error of the mean (SEM) values and statistical significance was determined using a paired or independent Student's $t$ test as appropriate.

\section{Fura-2 $\mathrm{Ca}^{2+}$ imaging}

For $\mathrm{Ca}^{2+}$ imaging, cultures were incubated for 1 hour in $\mathrm{NaCl}$-based extracellular solution containing $0.01 \mathrm{mM}$ fura-2AM (Sigma, $1 \mathrm{mM}$ stock in dimethylformamide).
The cells were then washed for 10-20 minutes with $\mathrm{NaCl}$ based extracellular solution to remove the extracellular fura-2AM, this period allowed cytoplasmic de-esterification of the $\mathrm{Ca}^{2+}$ sensitive fluorescent dye. The cells were constantly perfused with NaCl-based extracellular solution (1-2 $\mathrm{mL} / \mathrm{min}$ ) and viewed under an inverted Olympus BX50WI microscope. The fluorescence ratiometric images were taken with a KAI-1001 S/N 5B7890-4201 Olympus camera and the data obtained at excitation wavelengths of $340 \mathrm{~nm}$ and $380 \mathrm{~nm}$. Images were viewed and analysed using OraCal pro, Merlin morphometry temporal mode (Life Sciences resources, version 1.20). The DRG neurones were stimulated with $\mathrm{NaCl}$-based extracellular solution containing high $\mathrm{K}^{+}(30 \mathrm{mM})$, which produced depolarization, activation of voltage-gated $\mathrm{Ca}^{2+}$ channels and large transient increases in intracellular $\mathrm{Ca}^{2+}$. Three consistent transient increases in intracellular $\mathrm{Ca}^{2+}$ could be obtained in a single experiment on cultured DRG neurones [45] and no more than $8.5 \%$ variability was seen in any three-control responses from a single neurone [24]. The actions of soft coral samples $(100 \mu \mathrm{g} / \mathrm{mL})$ were investigated on the response to the second stimulus in DRG neurones and their actions on $\mathrm{Ca}^{2+}$ transient amplitude, duration at $1 / 2$ peak amplitude $\left(\mathrm{W}_{50}\right)$ and total $\mathrm{Ca}^{2+}$ flux were measured. The $\mathrm{W}_{50}$ value in seconds was determined by measuring the durations of the $\mathrm{KCl}$ evoked $\mathrm{Ca}^{2+}$ transients at the point of half their maximum amplitudes. This gives a standardized measurement of response duration. Total $\mathrm{Ca}^{2+}$ flux is the change in fluorescence ratio $\times$ duration of response, the values are given with respect to $\mathrm{Ca}^{2+}$ flux of 0.2 ratio units $\times 100 \mathrm{~s}$. By cutting out and weighing records we obtained values for the areas under the curves for $\mathrm{Ca}^{2+}$ transients. All experiments were conducted at room temperature and data are expressed as means \pm SEM.

\section{Abbreviations}

c.Lobo, crude sample from Lobophyton crassum

CPM, 3-carboxyl-1-methyl pyridinium (hydrochloride salt synthetic)

c.Sg, crude sample from Sarcophyton glaucum

c.Sl, crude sample from Sinularia leptoclados

DRG, Dorsal root ganglion.

NGF, Nerve growth factor

PKC, Protein kinase C

p.Sg, purified sample from Sarcophyton glaucum 


\section{Authors' contributions}

TT collected the soft coral specimens and participated in the biological characterization. WH and MJ carried out chemical analysis, purification and chemical identification of 3-carboxyl-1-methyl pyridinium. The electrophysiology and calcium imaging was conducted by WH, DW, KW, SN and RS. TT and RS conceived of the study and all authors read and approved the final manuscript.

\section{Acknowledgements}

Tarek Temraz and Roderick Scott thank the British Council in Egypt for travel support and providing the opportunity for this collaboration. We would also like to thank the Marine Science Department in Suez Canal University for providing the diving equipment and assistance. Wael Houssen thanks the Egyptian Government for a Ph.D. scholarship. We thank the EPSRC National Mass Spectrometry Centre, University of Wales Swansea, for mass spectrometric analysis and Dr lan Duce and Professor Samy Zalat for helpful discussion during the initial stages of this project. We would also like to thank the EEAA (Egyptian Environmental affairs agency) for allowing the collection soft coral samples.

\section{References}

I. Mayer AMS, Hamann MT: Marine Pharmacology in 2000: Marine compounds with antibacterial, anticoagulant, antifungal, anti-inflammatory, antimalarial, antiplatelet, antituberculosis, and antiviral activities; affecting the cardiovascular, immune, and nervous systems and other miscellaneous mechanisms of action. Mar Biotechnol 2004, 6:37-52.

2. Butler MS: Natural products to drugs: natural product derived compounds in clinical trials. Nat Prod Rep 2005, 22:162-195.

3. Sennett SH, McCarthy PJ, Wright AE, Pomponi SA: Natural products from marine invertebrates: The Harbor Branch Oceanographic Institution experience. Pharmaceutical News 2002, 9:483-488

4. Edwards AJ, Head SM: Key Environments-Red Sea. Pergamon Press, Oxford; 1987:440.

5. Paul V], Puglisi MP: Chemical mediation of interactions among marine organisms. Nat Prod Rep 2004, 21:189-209.

6. Scott RH, Whyment AD, Foster A, Gordon KH, Milne BF, Jaspars M: Analysis of the structure and electrophysiological actions of halitoxins: I,3 alkyl-pyrdinium salts from Callyspongia ridleyi. J Membr Biol 2000, I 76: I | 9-I3I.

7. Tucker SJ, McClelland D, Jaspars M, Sepčić K, MacEwan DJ, Scott RH: The influence of alkyl pyridinium sponge toxins on membrane properties, cytotoxicity, transfection and protein expression in mammalian cells. Biochim Biophys Acta 2003, 1614:17|-181.

8. McClelland D, Evans RM, Abidin I, Sharma S, Choudhry FZ, Jaspars M, Sepčić K, Scott RH: Irreversible and reversible pore formation by polymeric alkylpyridinium salts (Poly-APS) from the sponge Reniera sarai. Br J Pharmacol 2003, I39:1399-1 408.

9. Scott RH, Tucker SJ, Evans RM, MacEwan DJ, Jaspars M, Sepčić K: Cell membrane permeabilisation by alkylpyridinium sponge toxin preparations and their utilisation as novel transfection reagents. Proceedings of Neurotox 2003. Neurotoxicological Targets from Functional Genomics and Proteomics 2004:5 I-58.

10. Badria FA, Guirguis AN, Perovic S, Steffen R, Muller WEG, Schroder HC: Sarcophytolide: a new neuroprotective compound from soft coral Sarcophyton glaucum. Toxicology 1998, I 3 I: I33-143.

II. Rezanka T, Dembitsky VM: Brominated oxylipins and oxylipin glycosides from Red Sea corals. Euro J Org Chem 2002, 2003:309-316.

12. ElSayed KA, Hamann MT: A new norcembranoid dimer from theRed Sea soft coral Sinularia gardineri. I Nat Prod 1996, 59:687-689.

13. Abramson SN, Fenical W, Taylor P: Lophotoxins- Irreversible active-site-directed inhibitors of nicotinic acetylcholine receptors. Drug Dev Res 1991, 24:297-312.

14. Tornoe C, Bai D, Holden-Dyer L, Abramson SN, Sattelle DB: Actions of neurotoxins (bungarotoxins, neosurugatoxin and lophotoxins) on insect and nematode nicotinic acetylcholine receptors. Toxicon 1995, 33:4II-424.

15. Tosteson MT, Scriven DRL, Bharadwaj AK, Kishi Y, Tosteson DC: Interaction of palytoxin with red cells structure-function studies. Toxicon 1995, 33:799-807.

16. Roa MR, Venkatesham U, Reddy MVR, Venkateswarlu Y: An unusual novel C-29 steroid from the soft coral Lobophytum crassum. J Nat Prod 1999, 62:785-786.

17. Anjaneyulu ASR, Rao NSK, Sagar KS: Two new cembranoids from the soft coral Lobophytum catalai Tixier-Durivault of the Andaman and Nicobar Islands. Indian J Chem 1998, 37:267-274.

18. Radwan FE, Aboul-Dahab HM, Bumett JW: Some toxicological characteristics of three venomous soft corals from the Red Sea. Comp Biochem Physiol C 2002, 132:25-35.

19. Kelman D, Benayahu Y, Kashman Y: Chemical defence of the soft coral Parerythropodium fulvum fulvum (Forskall) in the Red Sea against generalist reef fish. J Exp Mar Biol Ecol 1999 , 238: $127-137$.

20. Slattery M, Hines GA, Starmer J, Paul VJ: Chemical signals in gametogenesis, spawning and larval settlement and defense of the soft coral Sinularia polydactyla. Coral Reefs 1999, 18:75-84.

21. Cafieri F, Fattorusso E, Taglialatela-Scafati O: NovelBetaines from the Marine Sponge Agelas dispar. J Nat Prod 1998, 6 I: I I7 I-I I 73.

22. McClintock JB, Baker BJ, Hamann MT, Yoshida W, Slattery M, Heine JN, Bryan PJ, Jayatilake GS, Moon BH: Homarine as a feeding deterrent in common shallow water Antarctic lamellarian gastropod Marseniopsis mollis: rare example of chem defence in marine prosobranch. J Chem Ecol 1994, 20:2539-2549.

23. Ghosal S, Dutta SK: Alkaloids of Abrus precatorius. Phytochem 1971, 10:195-198.

24. McClelland D, Evans RM, Barkworth L, Martin DJ, Scott RH: A study comparing the actions of gabapentin and pregabalin on the electrophysiological properties of cultured DRG neurones from neonatal rats. BMC Pharmacol 2004, 4:14 [http:// www.biomedcentral.com/content/pdf/|47|-2210-4-|4.pdf].

25. Gallego R, Eyzaguirre C: Membrane and action potential characteristics of $A$ and $C$ nodose ganglion cells studied in whole ganglia and in tissue slices. J Neurophysiol 1978, 41:1217-1232.

26. Safronov BV, Bischoff U, Vogel $\mathrm{W}$ : Single voltage-gated $\mathbf{K}^{+}$channels and their functions in small dorsal root ganglion neurones of rat. J Physiol (Lond) 1996, 493:393-408.

27. Pitcher GM, Henry JL: Mediation and modulation by eicosanoids of responses of spinal dorsal horn neurones to glutamate and substance $P$ receptor agonists: results with indomethacin in the rat in vivo. Neuroscience 1999, 93:II09-1I2I.

28. Vanegas $\mathrm{H}$, Schaible $\mathrm{H}$ : Prostaglandins and cyclooxygenases in the spinal cord. Prog Neurobiol 200I, 64:327-363.

29. Herbert JM, Augereau JM, Gleye J, Maffrand JP: Chelerythrine is a potent and specific inhibitor of protein kinase $\mathbf{C}$. Biochem Biophys Res Commun 1990, 172:993-999.

30. Siefker B, Kroiher M, Berking S: Induction of metamorphosis from the larval to the polyp stage is similar in Hydrozoa and a subgroup of Scyphozoa (Cnidaria, Semaeostomeae). Helgol Mar Res 2000, 54:230-236.

31. Cutignano A, Tramice A, De Caro S, Villani G, Cimino G, Fontana A: Biogenesis of 3-alkylpyridine alkaloids in the marine mollusc Haminoea orbignyana. Angewandte Chemie Int edition 2003, 42:2633-2636.

32. Bonham CC, Wood KV, Yang W], Nadolska-Orczyk A, Samaras $Y$, Gage DA, Poupart J, Burnet M, Hanson AD, Rhodes D: Identification of quaternary ammonium and tertiary sulfonium compounds by plasma desorption mass spectrometry. I Mass Spectrom 1995, 30: I 187-1194.

33. Taguchi $\mathrm{H}$ : Biosynthesis and metabolism of trigonelline, and physiological action of the compound. Vitamins 1988, 62:549-557

34. Tramontano WA, Jouve D: Trigonelline accumulation in saltstressed legumes and the role of other osmoregulators as cell cycle control agents. Phytochem 1997, 44:1037-1040.

35. Tohda C, Nakamura N, Komatsu K, Hattori M: Trigonellineinduced neurite outgrowth in human neuroblastoma SK-NSH cells. Biol Pharm Bull 1999, 22:679-682. 
36. Diochot S, Schweitz H, Béress L, Lazdunski M: Sea anemone peptides with a specific blocking activity against the fast inactivating channel Kv3.4. J Biol Chem 1998, 273:6744-6749.

37. Yeung SYM, Thompson D, Wang Z, Fedida D, Robertson B: Modulation of Kv3 subfamily potassium currents by the sea anemone toxin BDS: significance for CNS and biophysical studies. J Neurosci 2005, 25:8735-8745.

38. Terlau HK, Shon M, Grilley M, Stocker W, StÜhmer W, Olivera BM: Straegy for rapid immobilization of prey by a fish-hunting marine snail. Nature 1996, 38I:|48-I5I.

39. Houssen WE, Jaspars M, Wease KN, Scott RH: Acute actions of marine toxin latrunculin $A$ on the electrophysiological properties of cultured dorsal root ganglion neurones. Comp Biochem Physiol C 2006, I 42:19-29.

40. Gold MS, Shuster MJ, Levine JD: Characterization of six voltagegated $\mathrm{K}^{+}$currents in adult rat sensory neurons. J Neurophysiol 1996, 75:2629-2646.

41. Temraz TA, Abu Zaid MM: Distribution of butterflyfishes (Chaetodontidae) along the Egyptian Red Sea coast and its relation to coral health. J Aquatic Conservation 2005, I5:S59-S70.

42. Verseveldt J: A revision of the genus Sarcophyton Lesson (Octocorallia, Alconacea). Zoologische Verhandelingen Leiden 1982, 192:1-91.

43. Dolphin AC, Scott RH: Calcium channel currents and their inhibition by (-)-baclofen in rat sensoryneurones: modulation by guanine nucleotides. J Physiol (Lond) 1987, 386: I- 17.

44. Evans RM, Scott RH, Ross RA: Multiple actions of anandamide on neonatal rat cultured sensory neurones. $\mathrm{Br} J$ Pharmacol 2003, I 4I: /223-33

45. Sutton KG, Martin DJ, Pinnock RD, Lee K, Scott RH: Gabapentin inhibits high-threshold calcium channel currents in cultured rat dorsal root ganglion neurones. Br J Pharmacol 2002 135:257-65.

Publish with Bio Med Central and every scientist can read your work free of charge

"BioMed Central will be the most significant development for disseminating the results of biomedical research in our lifetime. "

Sir Paul Nurse, Cancer Research UK

Your research papers will be:

- available free of charge to the entire biomedical community

- peer reviewed and published immediately upon acceptance

- cited in PubMed and archived on PubMed Central

- yours - you keep the copyright 